\title{
Theoretical DFT Studies on Free Base, Cationic and Hydrochloride Species of Narcotic Tramadol Agent in Gas Phase and Aqueous Solution
}

\author{
José Ruiz Hidalgo $^{1(\mathbb{D})}$, Silvia Antonia Brandán 1 , *(D) \\ 1 Cátedra de Química General, Instituto de Química Inorgánica, Facultad de Bioquímica, Química y Farmacia, Universidad \\ Nacional de Tucumán, Ayacucho 471, 4000, San Miguel de Tucumán, Tucumán, Argentina \\ * Correspondence: silvia.brandan@fbqf.unt.edu.ar; sbrandan@fbqf.unt.edu.ar;
}

Received: 4.01.2021; Revised: 27.012021; Accepted: 29.01.2021; Published: 7.0

\begin{abstract}
Theoretical studies based on the density functional theory (DFT) have been performed to study structural and vibrational properties of the free base, cationic, and hydrochloride species of narcotic tramadol agent in the gas phase and aqueous solution. In both media, B3LYP/6-31G* calculations were used while in solution, the self-consistent reaction field (SCRF) method together with the integral equation formalism variant polarised continuum (IEFPCM) and universal solvation model density (SMD) models have been employed because these models consider the solvent effects. The vibrational studies have revealed that the species cationic is present in the solid phase because the most intense band predicted for the hydrochloride in infrared and Raman spectra is not observed in the experimental spectra. The harmonic force fields, together with the normal internal coordinates and scaling factors, have allowed the complete vibrational assignments of 126, 129, and 132 vibration modes expected for the free base, cationic, and hydrochloride species, respectively, by using the SQMFF methodology. The cationic species evidence the most negative solvation energy and higher hydration in solution in agreement with its lower stability, while the hydrochloride species is the most reactive in solution. MK charges and NBO and AIM studies support cationic species' instability due to the positive charge on $\mathrm{N}$ atom. Comparisons of the experimental UV spectrum of hydrochloride tramadol with the predicted for the three species suggest that the free base, cationic, and hydrochloride species can be present in solution. Comparisons of predicted infrared, Raman, ${ }^{1} \mathrm{H}$, and ${ }^{13} \mathrm{C}$ NMR and electronic spectra for the free base, cationic, and hydrochloride species of tramadol with the corresponding experimental ones have evidenced reasonable correlations for the cationic species showing that this species present in the solid phase and in solution.
\end{abstract}

Keywords: tramadol; molecular structure; DFT calculations; vibrational spectra.

(C) 2021 by the authors. This article is an open-access article distributed under the terms and conditions of the Creative Commons Attribution (CC BY) license (https://creativecommons.org/licenses/by/4.0/).

\section{Introduction}

In pharmacology, the hydrochloride species are highly used as medicaments because these structural forms allow the oral bioavailability of drugs as bioactive molecules and their incorporation quickly as therapeutic agents, as mentioned by Veber et al. [1]. Other important factors must be taken into account in the design of new drugs, such as the presence of hydrogen bond acceptors and donor groups, as reported by Lipinski et al. [2]. Theoretical studies combined with experimental results have evidenced that in some antiviral, alkaloids, and narcotic species as well as in antihistaminic and anti-hypertensive agents, the free base and cationic forms should be studied together with the hydrochloride one because, in aqueous 
solution, the hydrochloride species is in its cationic form while the free base as cationic one [323]. In this work, the free base, cationic, and hydrochloride forms of narcotic tramadol were studied from a theoretical point of view combining DFT calculations with experimental available infrared, Raman, ${ }^{1} \mathrm{H}$ - and ${ }^{13} \mathrm{C}-\mathrm{NMR}$ and ultraviolet spectra in order to predict structural, electronic, topological and vibrational properties of its three forms [24]. In the free base, the $\mathrm{N}$ atom is a tertiary amine with three organic substituents, while the cationic has four organic substituents and, for this reason, it is a quaternary ammonium cation with a charged nitrogen center, as can be seen in Figure 1 . The $\mathrm{Cl}$ anion neutralizes the quaternary charged cation in the hydrochloride form, and its species is uncharged.

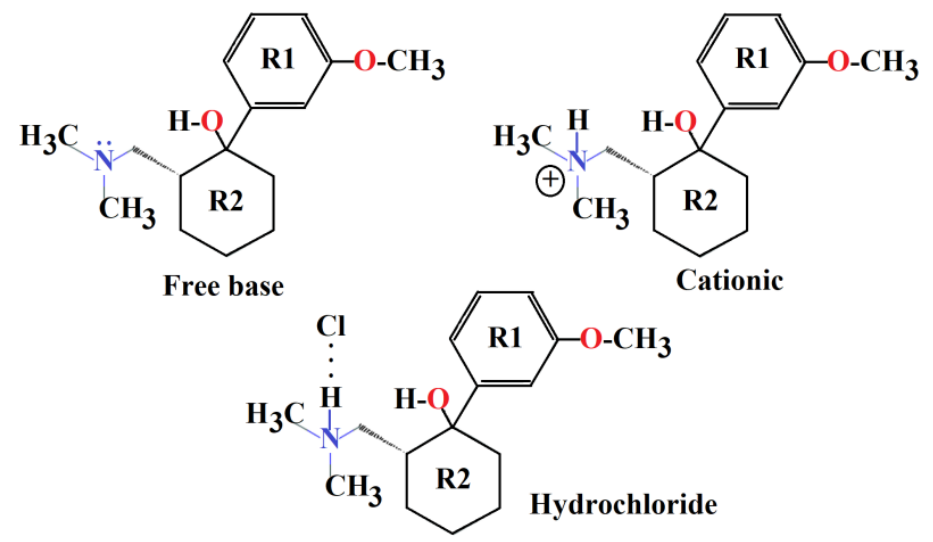

Figure 1. Structures of the free base, cationic, and hydrochloride forms of tramadol.

Then, complete vibrational assignments of those three forms of tramadol were performed by using the B3LYP/6-31G* method $[25,26]$ with the scaled quantum mechanical force fields (SQMFF) methodology, normal internal coordinates, transferable scaling factors, and the Molvib program [27-29]. A systematic chemical name of tramadol is (1RS,2RS)-2[(Dimethylamino)methyl]-1-(3-methoxyphenyl) cyclohexanol hydrochloride [30], while the experimental structure of tramadol hydrochloride was determined by X-ray diffraction by Kaduk et al. [31]. Other structures of Tramadol hydrochloride-benzoic acid (1/1) and of Tramadol hydrochloride and its acetonitrile solvate were also reported by Siddaraju et al. [32] and by Bag and Reddy [33], respectively. The physics and chemical properties of tramadol hydrochloride are known as well as its stability, pharmacokinetics, and metabolism, and, so far, only some vibration modes were published for this form of tramadol [24]. After optimizing three species in the gas phase and aqueous solution, the structural, electronic, topological, and vibrational properties were obtained together with their reactivities and behaviors in the two studied media. Later, the complete assignments of expected 126, 128, and 132 vibration modes of the free base, cationic, and hydrochloride forms of tramadol are reported together with the harmonic force fields the scaled force constants. The three forms of tramadol have the $\mathrm{N}$ $\left(\mathrm{CH}_{3}\right)_{2}$-group in its structures, as in antihistaminic promethazine and diphenydramine agents $[10,15]$, while in some alkaloids an only $\mathrm{N}-\mathrm{CH}_{3}$ group is found $[8-11,16]$. Hence, these $\mathrm{N}-\mathrm{CH} 3$ groups' presence plays a very important role in the chemical properties and biological activities of these pharmacological species. Here, comparisons of predicted infrared, Raman, ${ }^{1} \mathrm{H}-,{ }^{13} \mathrm{C}$ NMR, and ultraviolet-visible spectra of hydrochloride species of tramadol with the corresponding experimental ones show good correlations [24]. 


\section{Materials and Methods}

Firstly, the initial structure of the free base of tramadol was modeled with the GaussView program [34]. Then, to its structure was added an $\mathrm{H}$ atom to form the cationic later, to optimized cation was added a $\mathrm{Cl}$ atom to form the hydrochloride species. The three species were optimized in the gas and aqueous solutions with the Gaussian 09 program [35] and the B3LYP/6-31G* level of theory [25,26]. The self-consistent reaction force (SCRF) method was used to perform calculations in solution because this method, together with the integral equation formalism variant polarised continuum (IEFPCM) and universal solvation model density (SMD) models, consider the solvent effects [36-38]. The three structures of tramadol have two six member's rings, as shown in scheme 1. One of these rings is a methoxyphenyl, which is identified as R1, and the other one cyclohexanol, designed as R2. These identifications are important to perform the vibrational study by using the normal internal coordinates. The scaled quantum mechanical force fields (SQMFF) methodology and the Molvib program have allowed the determinations of harmonic force fields by using transferable scaling factors [2729]. After that, three species of tramadol's complete vibrational assignments were performed considering normal vibration modes potential energy distribution (PED) contributions $\geq 10 \%$. Good correlations were observed between the infrared and Raman spectra, particularly in the latter spectrum, when recognized equations were used to correct intensities activities [39,40]. Here, atomic charges, bond orders, molecular electrostatic potentials, stabilization energies, and topological properties were evaluated for the three species of tramadol in the two media by using natural bond orbital (NBO), atoms in molecules (AIM) calculations, and the MerzKollman (MK) scheme [41-44]. The GaussView and Moldraw programs were used to obtain the mapped MEP surfaces and volume variations of those three tramadol species $[34,45]$. In order to evaluate reactivities and behaviors of three species of tramadol, the frontier orbitals were employed to calculate the energy gap values and the chemical potential $(\mu)$, electronegativity $(\chi)$, global hardness $(\eta)$, global softness $(S)$, global electrophilicity index $(\omega)$ and global nucleophilicity index $(E)$ descriptors [3-17,46]. The ${ }^{1} \mathrm{H}$ and ${ }^{13} \mathrm{C} \mathrm{NMR}$ and electronic spectra were predicted in aqueous solution by using the gauge-including atomic orbital (GIAO) method and the Time-dependent DFT calculations (TD-DFT) by using the same level of theory $[35,47]$.

\section{Results and Discussion}

\subsection{Geometrical parameters and properties in both media.}

In Figure 2 are presented the optimized molecular structures of free base, cationic, and hydrochloride species of tramadol and atoms labeling while the R1 and R2 rings are shown in yellow and green colors. Some predicted properties for the tree species of tramadol in the gas phase and aqueous solution with the B3LYP/6-31G* method can be seen in Table 1. Thus, energy values, dipole moments, volumes, and variations are shown for each different media species. Note that in Table 1 the total E corrected by zero points vibrational energy (ZPVE) is also presented. The results show that the three species in solution increase the dipole moments values while only in the cationic species is observed a contraction of volume in this medium because the other two species evidence expansions in solution. The higher volume variation is observed in the hydrochloride species in solution. It shows a higher expansion of volume and 
dipole moment value due to its higher hydration with water molecules. The size of $\mathrm{Cl}$ atom influences on those two properties.

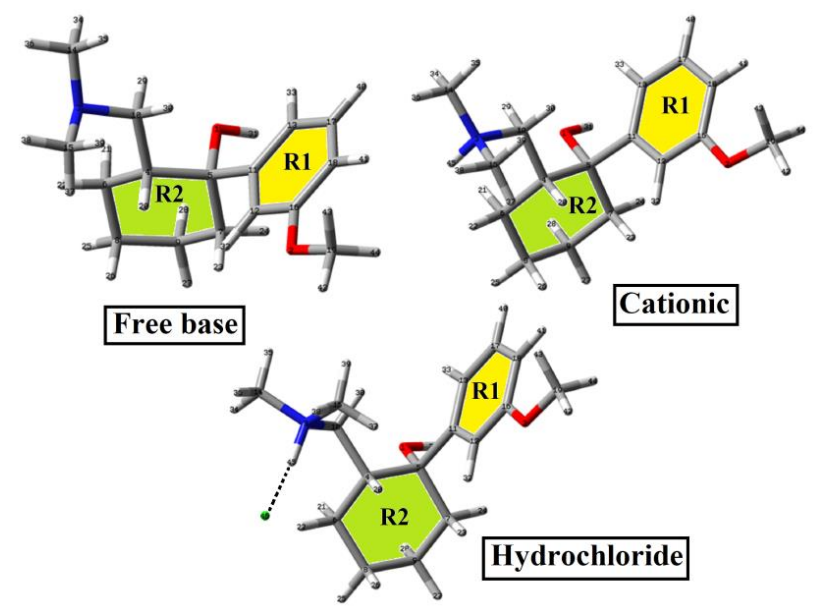

Figure 2. Molecular structures of the free base, cationic, and hydrochloride species of tramadol and atoms labeling. The two rings are shown in different colors.

Table 1. Calculated total energies $(E)$, dipole moments $(\mu)$ and volumes $(V)$ of the free base, cationic, and hydrochloride species of tramadol in the gas phase and aqueous solution by using the B3LYP/6-31G* method.

\begin{tabular}{|c|c|c|c|c|c|}
\hline \multicolumn{6}{|c|}{ B3LYP/6-31G* Method } \\
\hline Medium & E (Hartrees) & EZPVE (Hartrees) & $\mu(\mathrm{D})$ & $\mathrm{V}\left(\AA^{3}\right)$ & $\Delta \mathrm{V}\left(\AA^{3}\right)$ \\
\hline \multicolumn{6}{|c|}{ Free Base } \\
\hline GAS & -829.9342 & -829.5432 & 2.48 & 306.1 & \multirow{2}{*}{0.3} \\
\hline PCM/Water & -829.9462 & -829.5547 & 3.85 & 306.4 & \\
\hline \multicolumn{6}{|c|}{ Cationic } \\
\hline GAS & -833.3306 & -829.9239 & 10.06 & 310.9 & \multirow{2}{*}{1.0} \\
\hline PCM/Water & -830.4196 & -830.0125 & 12.32 & 309.9 & \\
\hline \multicolumn{6}{|c|}{ Hydrochloride } \\
\hline GAS & -1290.7572 & -1290.3523 & 10.06 & 333.2 & \multirow{2}{*}{7.5} \\
\hline PCM/Water & -1290.7939 & -1290.3871 & 16.38 & 340.7 & \\
\hline
\end{tabular}

Suppose now the positions and orientations of dipole moment values for the three species of tramadol in the gas phase are analyzed from Figure 3. In that case, important differences are observed in the tree species. For instance, in the free base, the vector is oriented from the $\mathrm{C} 4$ atom belonging to $\mathrm{R} 2$ ring to $\mathrm{C} 16$ atom linked to $\mathrm{O}-\mathrm{CH}_{3}$ group, between the $\mathrm{OH}$ and $\mathrm{O}-\mathrm{CH}_{3}$ groups, while in the cationic form, its vector is oriented from the $\mathrm{C} 11$ atom belonging to R1 toward the positively charged N3 atom. As in the free base, the dipole moment vector of hydrochloride species is directed from the $\mathrm{C} 4$ atom belonging to $\mathrm{R} 2$ ring to $\mathrm{C} 17$ atom belonging to $\mathrm{R} 1 \mathrm{ring}$, between the $\mathrm{OH}$ and $\mathrm{O}-\mathrm{CH}_{3}$ groups, in opposition to $\mathrm{Cl}$ atom. In solution, only changes in the magnitudes of dipole moments for the tree species are observed. The different values of dipole moment values in solution indicate that the three species are hydrated in different ways in aqueous solution, as evidenced in the volume variations. Hence, these changes are attributed to the different solvation energies, as was observed in various structural studies on the free base, cationic and hydrochloride species of some alkaloids, antihistaminic, anti-hypertensive and antiviral agents the cationic species [3-5,7,9-19,22,23]. Hence, the determinations of corresponding solvation energies are important in these three species of tramadol. 

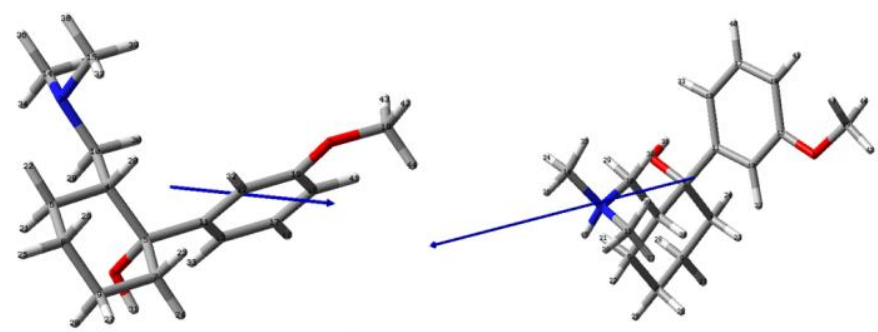

Free base

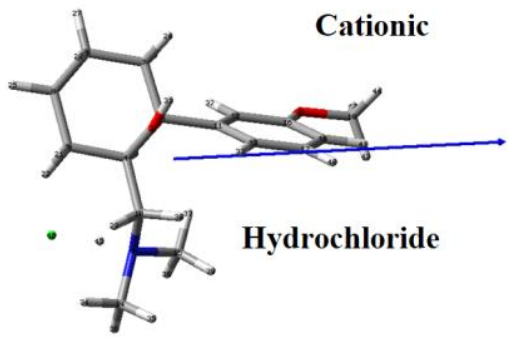

Figure 3. Orientations and directions of dipole moment vectors for the free base, cationic and hydrochloride species of tramadol in the gas phase by using the B3LYP/6-31G* method.

Table 2 summarizes corrected solvation energies by the total non-electrostatic terms and by zero points vibrational energy (ZPVE) for the free base, cationic, and hydrochloride species tramadol in the gas phase and aqueous solution by using the B3LYP/6-31G* method. Here, the results show a high $\Delta \mathrm{G}_{\mathrm{c}}$ value for the cationic form of tramadol, in agreement with some alkaloids, antihistaminic, anti-hypertensive, and antiviral agents [3-5,7,9-19,22,23]. The positively charged cationic species evidence higher hydration in the solution.

Table 2. Corrected solvation energies by the total non-electrostatic terms and by zero-point vibrational energy (ZPVE) of the free base, cationic, and hydrochloride species of Tramadol in the gas phase and aqueous solution by using the B3LYP/6-31G* method.

\begin{tabular}{l|l|l|l}
\hline \multicolumn{4}{c}{ B3LYP/6-31G* method ${ }^{\mathrm{a}}$} \\
\hline \multicolumn{4}{c}{ Solvation energy $(\mathrm{kJ} / \mathrm{mol})$} \\
\hline Fredium & $\Delta \mathrm{G}_{\mathrm{un}}{ }^{*}$ & $\Delta \mathrm{G}_{\mathrm{ne}}$ & \multicolumn{1}{c}{$\Delta \mathrm{G}_{\mathrm{c}}$} \\
\hline \multicolumn{4}{c}{ Free Base } \\
\hline PCM/Water & -30.16 & 22.02 & -52.18 \\
\hline \multicolumn{4}{c}{ Cationic } \\
\hline PCM/Water & -232.39 & 34.90 & -267.29 \\
\hline PCM/Water & -91.28 & 32.18 & -123.46 \\
\hline
\end{tabular}

$\Delta \mathrm{G}_{\mathrm{un}}{ }^{*}=$ uncorrected solvation energy, $\Delta \mathrm{G}_{\mathrm{ne}}=$ total non electrostatic terms, $\Delta \mathrm{G}_{\mathrm{c}}=$ corrected solvation energies. ${ }^{\mathrm{a}}$ This work

When the $\Delta \mathrm{G}_{\mathrm{c}}$ values for the three species of tramadol are compared in Table 3 with the values for other species with different biological activities such as alkaloids, antihistaminic and antiviral agents by using the B3LYP/6-31G* method, we observed that in all cases, the cationic species evidence higher $\Delta \mathrm{G}_{\mathrm{c}}$ values due to that the positive charges on $\mathrm{N}$ atoms produce higher hydrations in aqueous solution. The behaviors of $\Delta \mathrm{G}_{\mathrm{c}}$ of these species can be seen in Figure 4. Note that the species of tramadol are indicated as (Tra), amadantine or amantadine as (A) [23], naloxone (N) [16], $\mathrm{R}(+)$ forms of promethazine (P) [15], cyclizine (Cy) [11], morphine (M) [3], cocaine (Co) [5], scopolamine (S) [9], heroin (H) [7] and tropane (Tro) $[4,23]$. Figure 4 shows that the $\Delta \mathrm{G}_{\mathrm{c}}$ values for all free base and hydrochloride species follow approximately the same tendencies while the hydrochloride ones show different behavior. 
Table 3. Corrected solvation energies by the total non-electrostatic terms and zero-point vibrational energy (ZPVE) of different species in aqueous solution using the B3LYP/6-31G* method.

\begin{tabular}{l|c|c|c|c}
\hline \multicolumn{5}{c}{ B3LYP/6-31G* method } \\
\hline $\mathrm{N}^{\mathrm{o}}$ & Species $^{\mathrm{S}}$ & Free base & Cationic & Hydrochloride \\
\hline 1 & Tramadol $^{\mathrm{a}}$ & 52.18 & -267.29 & -123.46 \\
\hline 2 & Amantadine $^{\mathrm{b}}$ & -23.07 & -276.35 & -115.03 \\
\hline 3 & Naloxone $^{\mathrm{c}}$ & -100.75 & -302.45 & -122.28 \\
\hline 4 & $\mathrm{R}(+)$-Promethazine $^{\mathrm{d}}$ & -17.87 & -262.81 & -52.02 \\
\hline 5 & Cyclizine $^{\mathrm{e}}$ & -29.53 & $-244.36^{\#}$ & -105.06 \\
\hline 6 & Morphine $^{\mathrm{f}}$ & -60.91 & -309.19 & -144.74 \\
\hline 7 & Cocaine $^{\mathrm{g}}$ & -71.26 & -255.24 & -138.14 \\
\hline 8 & Scopolamine $^{\mathrm{h}}$ & -75.47 & -310.34 & -122.74 \\
\hline 9 & Heroin $^{\mathrm{i}}$ & -88.67 & -323.14 & -161.94 \\
\hline 10 & Tropane $^{\mathrm{b}, \mathrm{j}}$ & -12.55 & -244.33 & -87.18 \\
\hline
\end{tabular}

$\Delta \mathrm{G}_{\mathrm{c}}=$ corrected solvation energies, ${ }^{\mathrm{a}}$ This work, ${ }^{\mathrm{b}}$ From Ref [23], ${ }^{\mathrm{c}}$ From Ref [16], ${ }^{\mathrm{d}}$ From Ref [15], ${ }^{\mathrm{e}}$ From Ref [11], ${ }^{\mathrm{f}}$ From Ref [3], ${ }^{\mathrm{g}}$ From Ref [5], ${ }^{\mathrm{h}}$ From Ref [9], ${ }^{\mathrm{i}}$ From Ref [7], ${ }^{\mathrm{j} F r o m}$ Ref [4,23], ${ }^{\#}$ Cation cyclizine: $6-31+\mathrm{G}^{*}$

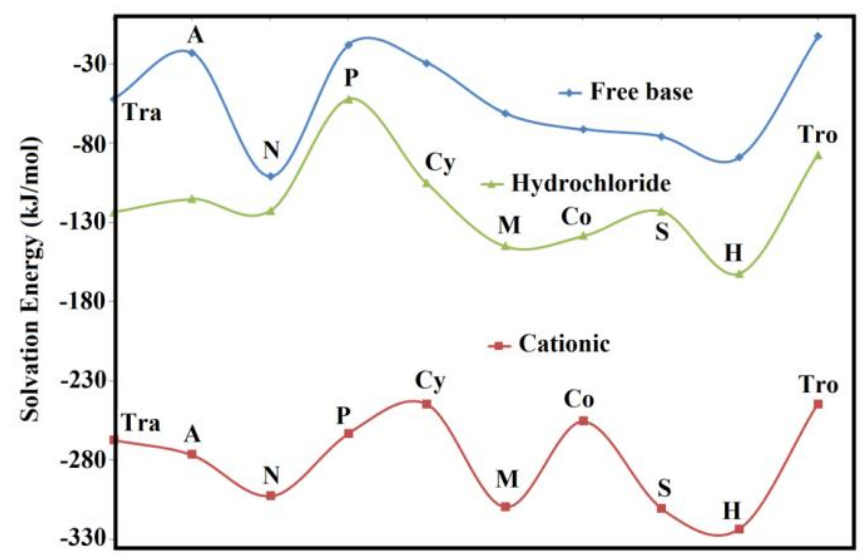

Figure 4. Comparisons of corrected solvation energies of the free base, cationic, and hydrochloride species of tramadol corresponding to alkaloids, antihistaminic and antiviral agents by using the B3LYP/6-31G* method.

On the contrary, the cationic species are most hydrated in aqueous solution and, hence, the $\Delta \mathrm{G}_{\mathrm{c}}$ values are highly negative, evidencing the highest negative value of the species of heroin. Thus, the free base of naloxone and the cationic and hydrochloride species of heroin have the most negative values, while the free base and cationic species of tropane and the hydrochloride one of promethazine present the lowest values. On the other side, the cationic form of naloxone shows approximately a similar value to morphine and scopolamine species. Studies in a solution of antiviral agents have suggested that the presence of acceptors and donors groups in the structures play an important role in the $\Delta \mathrm{G}_{\mathrm{c}}$ values [23]. Hence, the lower $\Delta \mathrm{G}_{\mathrm{c}}$ values observed for the free base and cationic species of tropane, amantadine, or cyclicine probably could be attributed to the presence of only a tertiary and/or quaternary $\mathrm{N}$ atoms belong to $>\mathrm{N}-\mathrm{CH}_{3}$ groups while in the compared species, other acceptors and donors groups are present in its structures in addition to $\mathrm{N}$ atoms $[4,8,11,23]$.

Comparisons of geometrical parameters for the three tramadol species using the B3LYP/6-31G* method with the corresponding experimental values determined for the crystal structure of tramadol hydrochloride by Kaduk et al. can be seen in Table 4 [31].

Note that the root-mean-square deviation (RMSD) values are used to compare bond lengths and angles. In general, good correlations between theoretical and experimental results were found for the three tramadol species with RMSD values of 0.017-0.010 ̊ for bond lengths and of $1.61-1.54^{\circ}$ for bond angles. 
Table 4. Comparisons between calculated geometrical parameters for the three Tramadol species in the gas phase and aqueous solution with the corresponding experimental ones.

\begin{tabular}{|c|c|c|c|c|c|c|c|}
\hline \multicolumn{7}{|c|}{ B3LYP/6-31G* Method ${ }^{\mathrm{a}}$} & \multirow{3}{*}{ Experimental $^{\mathrm{b}}$} \\
\hline \multirow{2}{*}{ Parameters } & \multicolumn{2}{|c|}{ Free Base } & \multicolumn{2}{|c|}{ Cationic } & \multicolumn{2}{|c|}{ Hydrochloride } & \\
\hline & Gas & PCM & Gas & PCM & Gas & $\mathbf{P C M}$ & \\
\hline \multicolumn{8}{|c|}{ Bond lengths (£) } \\
\hline $\mathrm{O} 1-\mathrm{C} 5$ & 1.437 & 1.441 & 1.433 & 1.438 & 1.436 & 1.438 & 1.430 \\
\hline $\mathrm{C} 5-\mathrm{C} 11$ & 1.538 & 1.539 & 1.537 & 1.539 & 1.539 & 1.539 & 1.546 \\
\hline C5-C7 & 1.551 & 1.549 & 1.546 & 1.548 & 1.549 & 1.548 & 1.542 \\
\hline $\mathrm{C} 5-\mathrm{C} 4$ & 1.558 & 1.561 & 1.566 & 1.562 & 1.558 & 1.562 & 1.563 \\
\hline C7-C9 & 1.533 & 1.532 & 1.533 & 1.532 & 1.533 & 1.532 & 1.510 \\
\hline C9-C8 & 1.533 & 1.531 & 1.532 & 1.531 & 1.532 & 1.531 & 1.529 \\
\hline C8-C6 & 1.533 & 1.533 & 1.536 & 1.534 & 1.532 & 1.533 & 1.529 \\
\hline C6-C4 & 1.540 & 1.541 & 1.543 & 1.543 & 1.543 & 1.541 & 1.542 \\
\hline $\mathrm{C} 4-\mathrm{C} 10$ & 1.541 & 1.540 & 1.534 & 1.534 & 1.543 & 1.534 & 1.547 \\
\hline C10-N3 & 1.467 & 1.473 & 1.525 & 1.515 & 1.504 & 1.511 & 1.514 \\
\hline N3-C14 & 1.456 & 1.463 & 1.503 & 1.499 & 1.485 & 1.495 & 1.475 \\
\hline N3-C15 & 1.456 & 1.463 & 1.502 & 1.498 & 1.487 & 1.493 & 1.487 \\
\hline C11-C12 & 1.397 & 1.399 & 1.397 & 1.398 & 1.398 & 1.398 & 1.392 \\
\hline C11-C13 & 1.403 & 1.403 & 1.403 & 1.403 & 1.404 & 1.403 & 1.392 \\
\hline C13- C17 & 1.392 & 1.394 & 1.394 & 1.394 & 1.393 & 1.394 & 1.392 \\
\hline C17-C18 & 1.396 & 1.396 & 1.394 & 1.396 & 1.395 & 1.396 & 1.417 \\
\hline C18-C16 & 1.399 & 1.399 & 1.401 & 1.399 & 1.400 & 1.399 & 1.392 \\
\hline C16-C12 & 1.400 & 1.400 & 1.402 & 1.401 & 1.401 & 1.401 & 1.392 \\
\hline $\mathrm{C} 16-\mathrm{O} 2$ & 1.367 & 1.375 & 1.358 & 1.374 & 1.364 & 1.374 & 1.367 \\
\hline $\mathrm{O} 2-\mathrm{C} 19$ & 1.417 & 1.429 & 1.425 & 1.429 & 1.419 & 1.429 & 1.440 \\
\hline RMSD $^{\text {b }}$ & 0.017 & 0.014 & 0.013 & 0.011 & 0.010 & 0.010 & \\
\hline \multicolumn{8}{|c|}{ Bond angles $\left({ }^{\circ}\right)$} \\
\hline O1-C5-C11 & 110.62 & 110.50 & 111.39 & 110.74 & 110.58 & 110.68 & 109.7 \\
\hline O1-C5-C7 & 108.80 & 108.76 & 109.65 & 109.19 & 109.43 & 109.19 & 110.8 \\
\hline O1-C5-C4 & 105.46 & 105.95 & 103.91 & 105.56 & 104.71 & 105.67 & 104.4 \\
\hline C5-C7-C9 & 113.03 & 113.03 & 113.01 & 113.04 & 113.15 & 113.07 & 111.9 \\
\hline C7-C9-C8 & 110.71 & 110.64 & 110.82 & 110.76 & 110.67 & 110.71 & 112.5 \\
\hline C7-C5-C11 & 109.73 & 109.31 & 110.82 & 109.71 & 110.07 & 109.62 & 109.0 \\
\hline C7-C5-C4 & 110.25 & 110.48 & 110.04 & 110.04 & 110.45 & 110.14 & 109.8 \\
\hline C9-C8-C6 & 110.85 & 111.26 & 110.99 & 111.21 & 111.00 & 111.12 & 108.5 \\
\hline C8-C6-C4 & 112.72 & 112.86 & 112.21 & 112.27 & 112.30 & 112.47 & 113.0 \\
\hline C6-C4-C5 & 111.39 & 111.42 & 111.68 & 111.52 & 112.00 & 111.56 & 110.1 \\
\hline C6-C4-C10 & 110.86 & 112.18 & 112.29 & 112.35 & 110.63 & 112.23 & 111.9 \\
\hline C5-C4-C10 & 111.85 & 110.93 & 107.91 & 109.40 & 110.92 & 109.64 & 109.5 \\
\hline C4-C10-N3 & 112.99 & 115.32 & 113.83 & 114.42 & 112.78 & 115.54 & 114.2 \\
\hline C10-N3-C14 & 111.58 & 108.67 & 111.18 & 110.52 & 112.44 & 109.58 & 111.7 \\
\hline C10-N3-C15 & 112.51 & 111.32 & 112.91 & 113.36 & 112.59 & 113.70 & 112.2 \\
\hline C14-N3-C15 & 110.51 & 109.24 & 111.21 & 110.72 & 111.01 & 110.42 & 113.2 \\
\hline C4-C5-C11 & 111.84 & 111.74 & 110.80 & 111.47 & 111.44 & 111.43 & 113.0 \\
\hline C5-C11-C12 & 120.58 & 120.20 & 120.21 & 120.18 & 120.55 & 120.18 & 120.1 \\
\hline C5-C11-C13 & 120.94 & 121.32 & 120.90 & 121.17 & 120.94 & 121.25 & 120.0 \\
\hline C11-C13-C17 & 120.26 & 120.26 & 119.90 & 120.15 & 120.23 & 120.18 & 121.2 \\
\hline C13-C17-C18 & 121.30 & 121.37 & 121.35 & 121.37 & 121.30 & 121.38 & 118.2 \\
\hline C17-C18-C16 & 118.69 & 118.51 & 119.00 & 118.59 & 118.75 & 118.54 & 120.6 \\
\hline C18-C16-C12 & 120.06 & 120.29 & 119.74 & 120.25 & 120.00 & 120.27 & 120.0 \\
\hline C16-C12-C11 & 121.20 & 121.07 & 121.11 & 120.99 & 121.18 & 121.03 & 120.0 \\
\hline C12-C11-C13 & 118.46 & 118.46 & 118.88 & 118.62 & 118.50 & 118.56 & 120.0 \\
\hline C16-O2-C19 & 118.20 & 117.87 & 118.63 & 117.88 & 118.40 & 117.96 & 116.4 \\
\hline O2-C16-C18 & 124.60 & 124.27 & 124.92 & 124.30 & 124.67 & 124.35 & 122.7 \\
\hline $\mathrm{O} 2-\mathrm{C} 16-\mathrm{C} 12$ & 115.32 & 115.42 & 115.33 & 115.43 & 115.31 & 115.37 & 112.2 \\
\hline RMSD $^{\mathbf{b}}$ & 1.59 & 1.77 & 1.59 & 1.54 & 1.57 & 1.62 & \\
\hline \multicolumn{8}{|c|}{ Dihedral angles $\left({ }^{\circ}\right)$} \\
\hline $\begin{array}{c}\text { C19-O2-C16- } \\
\text { C18 }\end{array}$ & -0.06 & -1.99 & -3.74 & -2.47 & -0.78 & 3.27 & \\
\hline $\begin{array}{c}\text { C19-O2-C16- } \\
\text { C12 }\end{array}$ & 179.75 & 177.90 & 176.32 & 177.43 & 179.19 & -176.80 & \\
\hline C14-N3-C10-C4 & -158.43 & -173.91 & -166.88 & -171.66 & -151.75 & -179.03 & \\
\hline N3-C10-C4-C5 & -174.16 & -178.27 & 179.31 & -175.84 & -146.12 & -169.17 & \\
\hline O1-C5-C7-C9 & -61.29 & -61.91 & -59.73 & -61.28 & -61.79 & -61.66 & \\
\hline O1-C5-C11-C12 & -176.16 & -179.32 & -178.70 & -179.85 & -177.09 & 179.38 & \\
\hline
\end{tabular}

${ }^{\mathrm{a}}$ This work, ${ }^{\mathrm{b}} \operatorname{Ref}[31]$ 
The better correlations in bond lengths are observed for the hydrochloride species, as expected because the experimental data were determined for this species. The two N3-C14 and N3-C15 distances correspond to the $>\mathrm{N}-\left(\mathrm{CH}_{3}\right)_{2}$ groups are predicted with similar values in the three species and both media. Studies related to the behavior of bonds $\mathrm{N}-\mathrm{CH}_{3}$ lengths in some alkaloids, narcotics, and anti-histaminic agents in the gas phase and aqueous solution have evidenced that there are some correlations in their properties [8]. Hence, in Table 5 it is observed bond lengths between the $\mathrm{N}$ and $\mathrm{C}$ atoms of the $\mathrm{N}-\mathrm{CH}_{3}$ bonds belonging to the three tramadol species in the gas phase and aqueous solution by using B3LYP/6-31G* calculations. The results are compared in the same table with published for amadantine [23], naloxone [16], promethazine [15], cyclizine [11], cocaine [3], morphine [5], scopolamine [9], heroin [7] and tropane $[4,23]$ at the same level of theory. The hydrochloride forms of all the species were studied, except for scopolamine that was studied in its hydrobromide form [9].

Table 5. Bonds lengths observed between the $\mathrm{N}$ and $\mathrm{C}$ atoms of the $\mathrm{N}-\mathrm{CH}_{3}$ bonds belonging to the three tramadol species in the gas phase and in aqueous solution by using B3LYP/6-31G* calculations.

\begin{tabular}{l|c|c|c|c|c|c}
\hline \multirow{2}{*}{ Species } & \multicolumn{3}{|c|}{ Gas-phase } & \multicolumn{3}{c}{ Aqueous solution } \\
\cline { 2 - 7 } & Free base & Cationic & Hydrochloride & Free base & Cationic & Hydrochloride \\
\hline Tramadol $^{\mathrm{a}}$ & 1.456 & 1.503 & 1.486 & 1.463 & 1.498 & 1.494 \\
\hline Amantadine $^{\mathrm{b}}$ & 1.469 & 1.550 & 1.501 & 1.476 & 1.516 & 1.510 \\
\hline Naloxone $^{\mathrm{c}}$ & 1.459 & 1.468 & 1.523 & 1.517 & 1.513 & 1.521 \\
\hline $\mathrm{R}(+)$-promethazine $^{\mathrm{d}}$ & 1.460 & 1.508 & 1.487 & 1.468 & 1.501 & 1.496 \\
\hline Cyclizine $^{\mathrm{e}}$ & 1.453 & 1.453 & $\#$ & 1.459 & $\#$ & 1.489 \\
\hline Morphine $^{\mathrm{f}}$ & 1.453 & 1.500 & 1.483 & 1.460 & 1.497 & 1.493 \\
\hline Cocaine $^{\mathrm{g}}$ & 1.459 & 1.493 & 1.487 & 1.467 & 1.492 & 1.494 \\
\hline Scopolamine $^{\mathrm{h}, \gamma}$ & 1.462 & 1.492 & 1.491 & 1.466 & 1.491 & 1.493 \\
\hline Heroin $^{\mathrm{i}}$ & 1.453 & 1.501 & 1.483 & 1.460 & 1.498 & 1.492 \\
\hline Tropane $^{\mathrm{j}}$ & 1.458 & 1.496 & 1.478 & 1.467 & 1.491 & 1.486 \\
\hline
\end{tabular}

${ }^{\mathrm{a}}$ This work, ${ }^{\mathrm{b}}$ From Ref [23], ${ }^{\mathrm{c}}$ From Ref [16], ${ }_{\mathrm{d}}^{\mathrm{d}}$ From Ref [15], ${ }^{\mathrm{e}}$ From Ref [11], ${ }^{\mathrm{f}}$ From Ref [3], ${ }^{\mathrm{g}}$ From Ref [5], ${ }^{\mathrm{h}}$ From

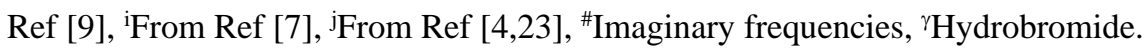

(a) GAS PHASE

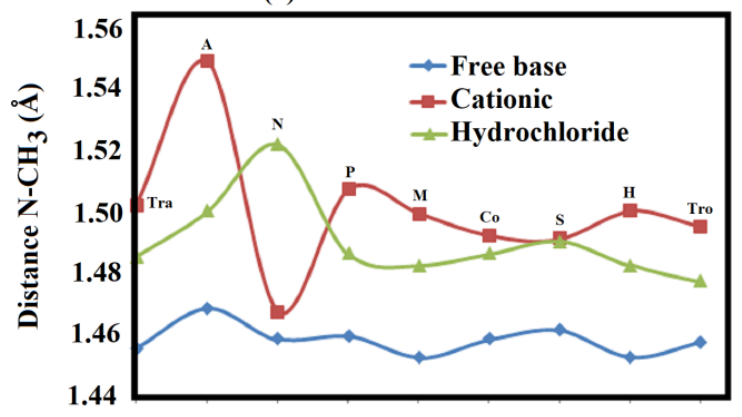

(b) Aqueous Solution

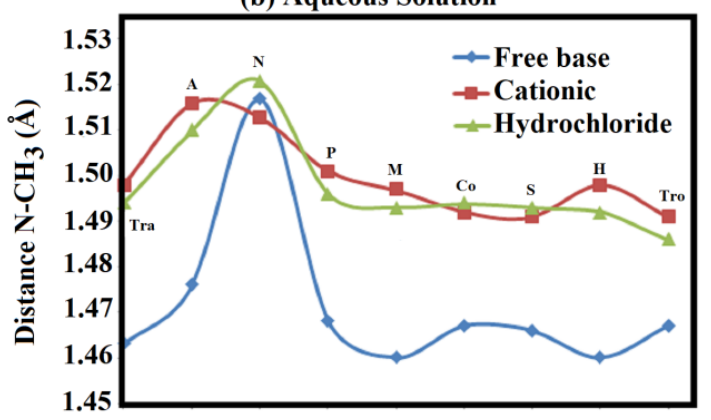

Figure 5. Bonds lengths observed between the $\mathrm{N}$ and $\mathrm{C}$ atoms of the $\mathrm{N}-\mathrm{CH}_{3}$ bonds belonging to the three tramadol species in the gas phase (a) and aqueous solution (b) by using B3LYP/6-31G* calculations compared with amadantine [23], naloxone [16], promethazine [15], cyclizine [11], cocaine [3], morphine [5], scopolamine [9], heroin [7] and tropane [4,23].

Figure 5 graphed the distances between $\mathrm{N}$ and $\mathrm{C}$ atoms of $\mathrm{N}-\mathrm{CH}_{3}$ groups for all compared species where their names have the same notation presented in Figure 4. The cyclizine species were not presented here because the cationic form in the gas phase and the hydrochloride one in solution present imaginary frequencies at the B3LYP/6-31G* level [11].

Here, it is necessary to clarify that the distance values presented in Table 5 for promethazine and tramadol correspond to average values because these species have two $\mathrm{N}$ $\left(\mathrm{CH}_{3}\right)_{2}$ groups. When Fig.5a is analyzed, we observed the lower distances for all free base species in the gas phase, showing values between 1.47 and $1.45 \AA$ while the presence of 
positive charges on the $\mathrm{N}$ atoms in all cationic species increases the distances slightly to values between 1.47 and $1.55 \AA$. The cationic species of amantadine and naloxone evidence the highest and lowest values, respectively, while the remaining species present values between 1.49 and $1.51 \AA$. These differences are quickly justified because in amantadine, the group is $\mathrm{N}-\mathrm{CC}_{3}$ group, while in naxolone is an allyl $>\mathrm{N}-\mathrm{CH}_{2}-\mathrm{CH}=\mathrm{CH}_{2}$ group different from the $\mathrm{N}-\mathrm{CH}_{3}$ group. On the other side, the hydrochloride species of naloxone present a higher value in the gas phase, while the tropane species present a lower value. In solution, the situation change because the cationic and hydrochloride species of all compared compounds reveal approximately the same behaviors and, where the cationic species of amantadine and the hydrochloride one of naloxone have the higher values. The similar behaviors for the cationic and hydrochloride species could indicate that the hydrochloride forms are as cationic ones in aqueous solution, while the differences observed between amantadine and naloxone could be justified by the presence of groups linked to quaternary $\mathrm{N}$ atoms different from $\mathrm{N}-\mathrm{CH}_{3}$, which are present in the other species. The free base of naloxone has a higher distance in solution due to the size of the allyl $>\mathrm{N}-\mathrm{CH}_{2}-\mathrm{CH}=\mathrm{CH}_{2}$ group. For the other species, the distances are around 1.47 and $1.46 \AA$. These different values in the $\mathrm{N}-\mathrm{C}$ distance evidence clearly that the groups linked to tertiary (free base species) or quaternary $\mathrm{N}$ atoms (cationic and hydrochloride species) affect the distances and, hence, on some properties of the compound.

\subsection{Atomic charges, molecular electrostatic potentials, and bond orders in both media.}

Previous structural and vibrational studies of pharmacological hydrochloride species with different biological activities have revealed that the hydrochloride species in aqueous solution are present in this medium as cationic ones [3-5,7,9-12,15-20,22,23] and, for these reasons, atomic charges, molecular electrostatic potentials (MEP), and bond orders (BO) are important properties that explain the behaviors of these species in different media.

Table 6. Mulliken, Merz-Kollman, and NPA charges (a.u.), molecular electrostatic potentials (MEP) (a.u.) and bond orders (BO), expressed as Wiberg indexes of three tramadol species in the gas phase and aqueous solution by using B3LYP/6-31G* calculations.

\begin{tabular}{|c|c|c|c|c|c|c|c|c|c|c|}
\hline \multicolumn{11}{|c|}{ Free base } \\
\hline \multicolumn{6}{|c|}{ Gas Phase } & \multicolumn{5}{|c|}{ PCM } \\
\hline Atoms & MK & Mulliken & NPA & MEP & $\mathrm{BO}$ & MK & Mulliken & NPA & MEP & $\mathrm{BO}$ \\
\hline $1 \mathrm{O}$ & -0.639 & -0.655 & -0.763 & -22.318 & 1.795 & -0.615 & -0.655 & -0.763 & -22.318 & 1.793 \\
\hline 20 & -0.335 & -0.509 & -0.523 & -22.285 & 2.121 & -0.339 & -0.516 & -0.525 & -22.286 & 2.114 \\
\hline $3 \mathrm{~N}$ & -0.168 & -0.370 & -0.504 & -18.368 & 3.116 & -0.228 & -0.376 & -0.496 & -18.368 & 3.110 \\
\hline \multicolumn{11}{|c|}{ Cationic } \\
\hline Atoms & MK & Mulliken & NPA & MEP & $\mathrm{BO}$ & MK & Mulliken & NPA & MEP & $\mathrm{BO}$ \\
\hline 10 & -0.620 & -0.662 & -0.387 & -22.199 & 1.785 & -0.597 & -0.661 & -0.772 & -22.201 & 1.784 \\
\hline 20 & -0.335 & -0.506 & -0.259 & -22.195 & 2.135 & -0.337 & -0.513 & -0.521 & -22.197 & 2.124 \\
\hline $3 \mathrm{~N}$ & 0.292 & -0.492 & -0.221 & -18.061 & 3.470 & 0.251 & -0.489 & -0.440 & -18.058 & 3.471 \\
\hline \multicolumn{11}{|c|}{ Hydrochloride } \\
\hline Atoms & MK & Mulliken & NPA & MEP & $\mathrm{BO}$ & MK & Mulliken & NPA & MEP & $\mathrm{BO}$ \\
\hline $1 \mathrm{O}$ & -0.634 & -0.656 & -0.766 & -22.301 & 1.792 & -0.624 & -0.654 & -0.764 & -22.295 & 1.793 \\
\hline 20 & -0.311 & -0.505 & -0.519 & -22.272 & 2.128 & -0.327 & -0.514 & -0.524 & -22.267 & 2.118 \\
\hline $3 \mathrm{~N}$ & 0.539 & -0.476 & -0.487 & -18.254 & 3.361 & 0.539 & -0.476 & -0.470 & -18.229 & 3.397 \\
\hline
\end{tabular}

For the three studies, the results only for the $\mathrm{O} 1, \mathrm{O} 2$, and $\mathrm{N} 3$ atoms corresponding to groups donor $(\mathrm{OH})$ and acceptors $\left(\mathrm{O}-\mathrm{CH}_{3}\right.$ and $\left.\mathrm{N}-\left(\mathrm{CH}_{3}\right)_{2}\right) \mathrm{H}$ bonds, respectively, are presented in Table 6. Hence, atomic Merz-Kollman (MK), Mulliken, and natural population (NPA) charge for the three tramadol species in both media by using the B3LYP/6-31G* method are given in Table 6, while Figure 6 are shown the behaviors of three charges on those three atoms of free base, cationic and hydrochloride species of tramadol in both media. An exhaustive 
inspection of graphic show different behaviors of three types of charges but the same in both media.

Thus, from the three different studied charges, only the MK ones evidence positive charges on $\mathrm{N} 3$ atoms of cationic and hydrochloride species in both media, as expected because these two species have four organic substituents and quaternary ammonium cations while the Mulliken and NPA charges on these atoms show negative values.
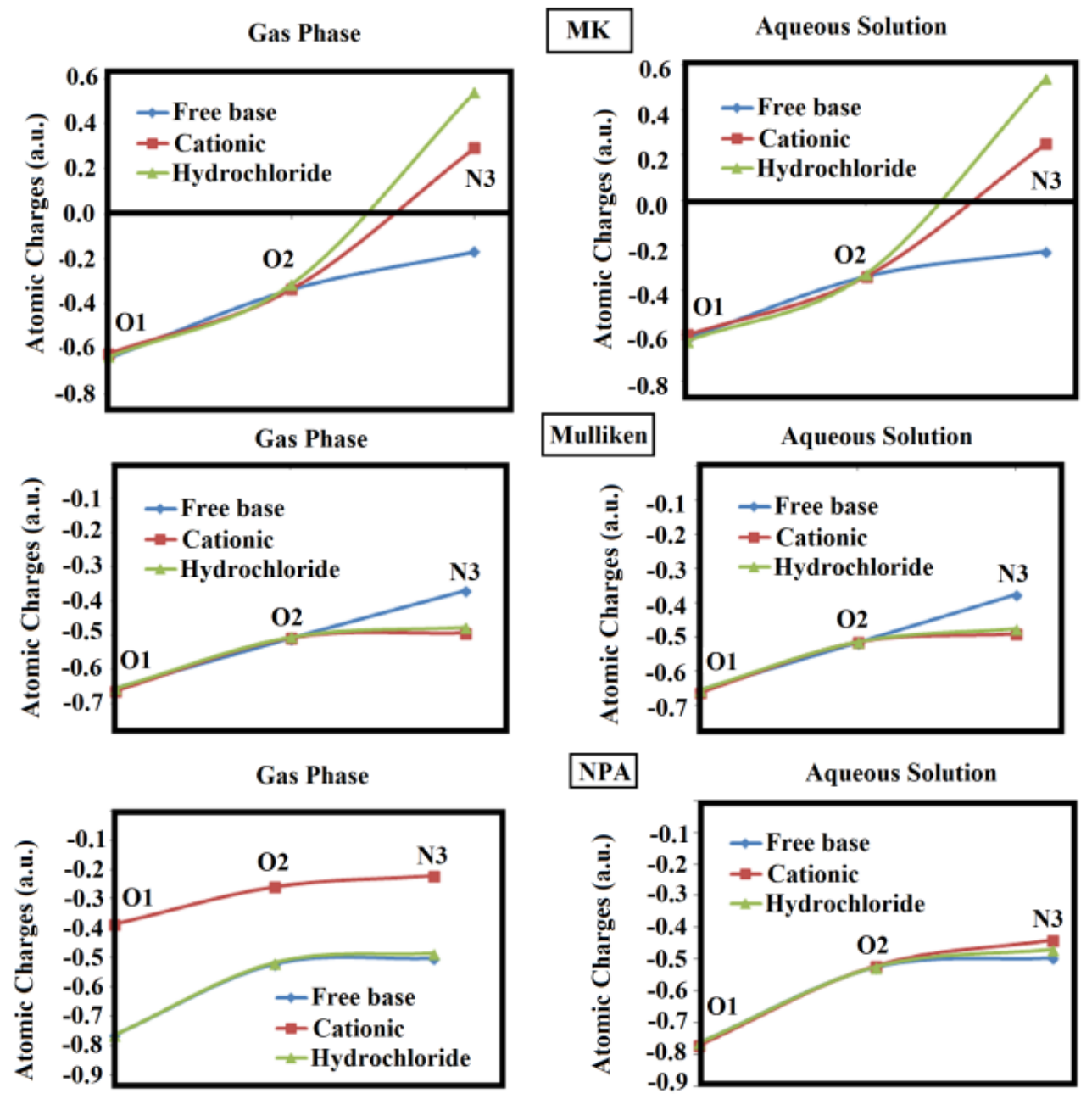

Figure 6. Behaviors of MK, Mulliken, and NPA charges on O1, O2 and N3 atoms of the free base, cationic, and hydrochloride species of tramadol in both media by using B3LYP/6-31G* calculations.

Negative MK charges are observed on N3 atoms of the free base in both media due to its pairs electrons available, while only the Mulliken charges on N3 of cationic and hydrochloride species have the same negative values. On the other hand, the behaviors of NPA charges for the three species of tramadol in the gas phase are different form in aqueous solution; thus, the three atoms of cationic species show values very high in the gas phase, as compared with the other two ones. In solution, the same NPA charges on the O1 and $\mathrm{O} 2$ atoms of three species are observed, while on N3 of cationic species, a slightly higher NPA charge is evidenced. Finally, the three types of charges reveal negative values on $\mathrm{O} 1$ and $\mathrm{O} 2$ atoms of three species in both media.

Regarding the molecular electrostatic potentials (MEP) on three O1, O2, and N3 atoms of three tramadol species from Table 6 carefully, we observed practically the same values for the free base in both media and, only slight changes are observed for the other two species, 
evidencing few variations on $\mathrm{O} 2$ and $\mathrm{N} 3$ of hydrochloride species in solution (0.025-0.005 a.u.). However, when the mapped MEP surfaces are built for the three species in the gas phase with the GaussView program [34], different regions and colorations are observed, as shown in Figure 7. The free base shows strong blue colors on H31, which belongs to O1-H31 group, while red colorations are observed on $\mathrm{O} 1, \mathrm{O} 2$, and $\mathrm{N} 3$ atoms that belong to $\mathrm{OH}, \mathrm{O}-\mathrm{CH}_{3}$, and $\mathrm{N}-\left(\mathrm{CH}_{3}\right)_{2}$ groups, respectively. The cationic species show strong blue color on the $\mathrm{N}-\left(\mathrm{CH}_{3}\right)_{2}$ groups due to the charge on $\mathrm{N} 3$, as expected because its species is positively charged, while the light blue color on the remaining atoms of a molecule. The hydrochloride species shows an extensive and strong red region around $\mathrm{Cl}$ atom and the other two orange regions on $\mathrm{O} 1$ and $\mathrm{O} 2$, while the strong blue color is observed on the $\mathrm{H} 31$ atom that belongs to $\mathrm{OH}$ group.

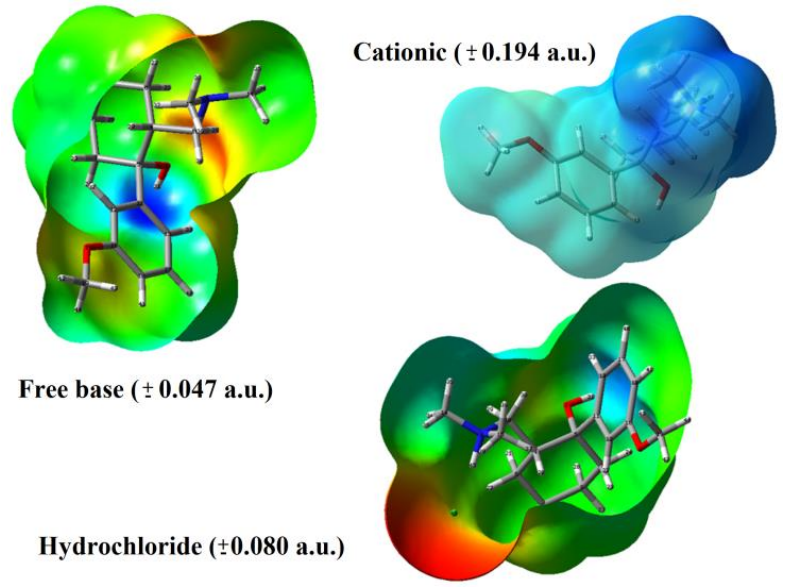

Figure 7. Calculated electrostatic potential surfaces on the molecular surfaces of the free base, cationic, and hydrochloride species of tramadol in the gas phase. B3LYP functional and 6-31G* basis set. Isodensity value of 0.005 .

Hence, the nucleophilic and/or electrophilic sites are evidenced in the three species by the red and blue colors, respectively, and, also, by the different calculated MEPs values. These mapped MEP surfaces are completely different in the three tramadol species and reveal regions in which reactions with potential biological electrophiles or nucleophiles occur.

Other interesting properties predicted for the three tramadol species with the NBO program by using the B3LYP/6-31* level of theory are the bond orders (BOs) totals by atom, expressed as Wiberg indexes [25,26]. Table 6 shows that $\mathrm{O} 2$ and $\mathrm{N} 3$ of cationic species present higher BOs values than $\mathrm{O} 1$ of the other two species. Note that $\mathrm{O} 1$ in the three species have the lower values, as expected, because this atom belongs to $\mathrm{OH}$ group and, for these reasons, these are the most labile. In the cationic species, the N3 has a higher BO value due to its charge. In solution, the BOs for the three species evidencing a decrease due to donors and acceptors groups' hydrations. Nevertheless, when the Wiberg bond index matrix in the Natural Atomic Orbital (NAO) basis for the H45-Cl46 bond is investigated for the hydrochloride species of tramadol it is observed a value of 0.343 in gas phase indicating a covalent character for this bond but, in solution, the value change to 0.213 because the character of bond slightly changes to ionic (N3-H45 ․ C146). A similar resulted was observed in the hydrochloride species of antiviral amantadine [23].

\subsection{NBO and AIM studies.}

The hydration in an aqueous solution of $\mathrm{OH}, \mathrm{O}-\mathrm{CH}_{3}$, and $\mathrm{N}\left(\mathrm{CH}_{3}\right)_{2}$ groups in the three species of tramadol could generate different types of interactions, which can be important, 
taking into account its stabilities and its use as a pharmacological drug [1,2]. Hence, the presence of a different type of interactions in those species has been studied with the NBO program using the second-order perturbation theory analyses of the Fock matrix in NBO Basis and with the AIM 2000 program by using the topological properties [41-43]. Therefore, the most important donor-acceptor interactions predicted for the three tramadol species in both media by using the B3LYP/6-31G* method and the NBO program are shown in Table 7.

Table 7. Main delocalization energies (in $\mathrm{kJ} / \mathrm{mol}$ ) of free base, cationic, and hydrochloride species of Tramadol in the gas phase and aqueous solution by using B3LYP/6-31G* calculations.

\begin{tabular}{|c|c|c|c|c|c|c|}
\hline \multirow{3}{*}{ Delocalization } & \multicolumn{6}{|c|}{ B3LYP/6-31G*a } \\
\hline & \multicolumn{2}{|c|}{ Free base } & \multicolumn{2}{|c|}{ Cationic } & \multicolumn{2}{|c|}{ Hydrochloride } \\
\hline & Gas & Water & Gas & Water & Gas & Water \\
\hline$L P(2) O 2 \rightarrow \sigma^{*} C 16-C 18$ & 127.03 & 123.64 & & & 130.75 & 125.23 \\
\hline$\Delta E_{L P \rightarrow \sigma^{*}}$ & 127.03 & 123.64 & & & 130.75 & 125.23 \\
\hline$L P(2) O 2 \rightarrow \pi^{*} C 12-C 16$ & & & 63.91 & & & \\
\hline$L P(2) O 2 \rightarrow \pi^{*} C 16-C 18$ & & & & 64.07 & & \\
\hline$\Delta E_{L P \rightarrow \pi^{*}}$ & & & 63.91 & 64.07 & & \\
\hline$\pi C 11-C 12 \rightarrow \pi^{*} C 13-C 17$ & 71.14 & 71.39 & & 33.98 & 70.39 & 70.14 \\
\hline$\pi C 11-C 12 \rightarrow \pi^{*} C 16-C 18$ & 97.14 & 97.78 & & 44.47 & 95.38 & 95.22 \\
\hline$\pi C 11-C 13 \rightarrow \pi^{*} C 17-C 18$ & & & 46.89 & & & \\
\hline$\pi C 12-C 16 \rightarrow \pi^{*} C 11-C 13$ & & & 50.36 & & & \\
\hline$\pi C 13-C 17 \rightarrow \pi^{*} C 11-C 12$ & 93.54 & 94.25 & & 49.11 & 94.21 & 95.59 \\
\hline$\pi C 13-C 17 \rightarrow \pi^{*} C 16-C 18$ & 70.97 & 70.85 & & 35.07 & 70.30 & 70.60 \\
\hline$\pi C 16-C 18 \rightarrow \pi^{*} C 11-C 12$ & 68.88 & 68.88 & & 37.36 & 69.84 & 70.26 \\
\hline$\pi C 16-C 18 \rightarrow \pi^{*} C 13-C 17$ & 94.42 & 94.71 & & 48.27 & 96.26 & 95.42 \\
\hline$\pi C 16-C 18 \rightarrow \pi^{*} C 11-C 12$ & 1089.68 & 1172.57 & & & & \\
\hline$\pi C 16-C 18 \rightarrow \pi^{*} C 13-C 17$ & 1210.11 & & & & & \\
\hline$\pi C 17-C 18 \rightarrow \pi^{*} C 12-C 16$ & & & 49.57 & & & \\
\hline$\Delta E_{\pi \rightarrow \pi^{*}}$ & 2795.88 & 1670.43 & 146.82 & 248.26 & 496.38 & 497.23 \\
\hline$\sigma N 3-C 10 \rightarrow L P * H 45$ & & & & & 43.97 & 58.23 \\
\hline$\sigma N 3-C 14 \rightarrow L P * H 45$ & & & & & 53.17 & 62.49 \\
\hline$\sigma N 3-C 15 \rightarrow L P * H 45$ & & & & & 54.17 & 58.64 \\
\hline$\Delta E_{\sigma \rightarrow L P *}$ & & & & & 151.31 & 179.36 \\
\hline$L P(1) N 3 \rightarrow L P * H 45$ & & & & & 1277.53 & 1531.72 \\
\hline$L P(4) C l 46 \rightarrow L P * H 45$ & & & & & 621.94 & 250.88 \\
\hline$\Delta E_{L P \rightarrow L P *}$ & & & & & 1899.47 & 1782.6 \\
\hline$\Delta E_{T O T A L}$ & 2922.91 & \begin{tabular}{|l|l|}
1794.07 \\
\end{tabular} & 210.73 & 312.33 & 2677.91 & 2584.42 \\
\hline
\end{tabular}

${ }^{a}$ This work

A detailed analysis of results reveals that the free base $\left(\Delta E_{L P \rightarrow \sigma^{*}}\right.$ and $\Delta E_{\left.\pi \rightarrow \pi^{*}\right)}$ and the cationic species $\left(\Delta E_{L P \rightarrow \pi^{*}}\right.$ and $\left.\Delta E_{\pi \rightarrow \pi^{*}}\right)$ in both media present two interactions while in the hydrochloride species four interactions are observed in both media $\left(\Delta E_{L P \rightarrow \sigma^{*}}, \Delta E_{\pi \rightarrow \pi^{*}}, \Delta E_{\sigma \rightarrow L P^{*}}\right.$ and $\Delta E_{L P \rightarrow L P *}$. The free base and hydrochloride species evidence lower stabilities in an aqueous solution, while the cationic one increases its stability in this medium, probably due to the positive charge on N3. Thus, the charged species justify their higher instability than the free base and hydrochloride ones with a total energy of $312.33 \mathrm{~kJ} / \mathrm{mol}$. On the other hand, the gas phase's the free base is most stable than the hydrochloride one in both media. The hydrochloride form is most stable in solution compared with the free base with a total energy of 2584.42 $\mathrm{kJ} / \mathrm{mol}$. The low stability in a solution of cationic species can probably be attributed to its hydration, as supported by the higher solvation energy or most negative value predicted for this species $(-267.29 \mathrm{~kJ} / \mathrm{mol})$.

According to Bader's theory, the characteristic or nature of intra-molecular, $\mathrm{H}$ bonds, ionic, and/or covalent, polar interactions can be studied with the topological properties by using the AIM 2000 program of atoms in molecules [42,43]. Hence, the electron density, $\rho(r)$, the Laplacian values, $\nabla^{2} \rho(r)$, the eigenvalues $(\lambda 1, \lambda 2, \lambda 3)$ of the Hessian matrix and, the $|\lambda 1| / \lambda 3$ 
ratio calculated in the bond critical points (BCPs) and ring critical points (RCPs) for the free base and cationic species of tramadol and the hydrochloride one in both media with the B3LYP/6-31G* method are shown in Tables 8 and 9, respectively.

Table 8. Analysis of the Bond Critical Points (BCPs) and Ring critical point (RCPs) for the free base and cationic species of Tramadol in the gas phase and aqueous solution by using the B3LYP/6-31G* method.

\begin{tabular}{|c|c|c|c|c|c|c|c|c|}
\hline \multicolumn{9}{|c|}{ Free base } \\
\hline \multirow{2}{*}{ Parameter ${ }^{\#}$} & \multicolumn{4}{|c|}{ GAS PHASE } & \multicolumn{4}{|c|}{ PCM } \\
\hline & H20---H37 & RCPN1 & RCP1 & $\mathrm{RCP} 2$ & H20---H37 & RCPN1 & $\mathrm{RCP1}$ & $\mathrm{RCP} 2$ \\
\hline$\rho(\mathrm{r})$ & 0.0094 & 0.0092 & 0.0200 & 0.0171 & 0.0099 & 0.0099 & 0.0199 & 0.0171 \\
\hline$\nabla^{2} \rho(r)$ & 0.0380 & 0.0428 & 0.1584 & 0.1084 & 0.0424 & 0.0452 & 0.1576 & 0.1080 \\
\hline$\lambda 1$ & -0.0092 & -0.0077 & -0.0147 & -0.0136 & -0.0087 & -0.0081 & -0.0147 & -0.0136 \\
\hline$\lambda 2$ & -0.0039 & 0.0048 & 0.0816 & 0.0570 & -0.0021 & 0.0023 & 0.0812 & 0.0571 \\
\hline$\lambda 3$ & 0.0514 & 0.0459 & 0.0915 & 0.0651 & 0.0533 & 0.0510 & 0.0912 & 0.0647 \\
\hline$|\lambda 1| / \lambda 3$ & 0.1789 & 0.1677 & 0.1606 & 0.2089 & 0.1632 & 0.1588 & 0.1611 & 0.2102 \\
\hline Distances $(\AA)$ & 2.162 & & & & 2.178 & & & \\
\hline \multicolumn{9}{|c|}{ Cationic } \\
\hline \multirow{2}{*}{ Parameter ${ }^{\#}$} & \multicolumn{4}{|c|}{ GAS PHASE } & \multicolumn{4}{|c|}{ PCM } \\
\hline & H22---H45 & RCPN1 & RCP1 & $\mathrm{RCP} 2$ & H22---H45 & RCPN1 & $\mathrm{RCP} 1$ & $\mathrm{RCP} 2$ \\
\hline$\rho(\mathrm{r})$ & 0.0118 & 0.0113 & 0.0200 & 0.0170 & 0.0100 & 0.0100 & 0.0200 & 0.0170 \\
\hline$\nabla^{2} \rho(r)$ & 0.0480 & 0.0540 & 0.1576 & 0.1076 & 0.0420 & 0.0448 & 0.1580 & 0.1080 \\
\hline$\lambda 1$ & -0.0117 & -0.0092 & -0.0147 & -0.0135 & -0.0093 & -0.0083 & -0.0147 & -0.0136 \\
\hline$\lambda 2$ & -0.0061 & 0.0077 & 0.0814 & 0.0575 & -0.0029 & 0.0033 & 0.0815 & 0.0575 \\
\hline$\lambda 3$ & 0.0660 & 0.0554 & 0.0912 & 0.0638 & 0.0546 & 0.0500 & 0.0913 & 0.0642 \\
\hline$|\lambda 1| / \lambda 3$ & 0.1772 & 0.1660 & 0.1611 & 0.2115 & 0.1703 & 0.1660 & 0.1610 & 0.2118 \\
\hline Distances $(\AA)$ & 2.029 & & & & 2.104 & & & \\
\hline
\end{tabular}

\#Parameters in a.u.

Table 9. Analysis of the Bond Critical Points (BCPs) and Ring critical point (RCPs) for the hydrochloride species of tramadol in the gas phase and aqueous solution by using the B3LYP/6-31G* method.

\begin{tabular}{|c|c|c|c|c|c|c|c|}
\hline \multicolumn{8}{|c|}{ Hydrochloride } \\
\hline \multicolumn{8}{|c|}{ GAS PHASE } \\
\hline Parameter ${ }^{\#}$ & C12---H37 & Cl46---H45 & Cl46---H22 & RCPN1 & RCPN2 & RCP1 & RCP2 \\
\hline$\rho(\mathrm{r})$ & 0.0044 & 0.0696 & 0.0099 & 0.0061 & 0.0040 & 0.0200 & 0.0170 \\
\hline$\nabla^{2} \rho(r)$ & 0.0136 & 0.0968 & 0.0312 & 0.0252 & 0.0124 & 0.1580 & 0.1080 \\
\hline$\lambda 1$ & -0.0027 & -0.1106 & -0.0081 & -0.0030 & -0.0014 & -0.0147 & -0.0136 \\
\hline$\lambda 2$ & -0.0022 & -0.1104 & -0.0068 & 0.0059 & 0.0037 & 0.0815 & 0.0572 \\
\hline$\lambda 3$ & 0.0187 & 0.3179 & 0.0463 & 0.0224 & 0.0105 & 0.0914 & 0.0645 \\
\hline$|\lambda 1| / \lambda 3$ & 0.1443 & 0.3479 & 0.1749 & 0.1339 & 0.1333 & 0.1608 & 0.2108 \\
\hline Distances $(\AA)$ & 2.980 & 1.778 & 2.764 & & & & \\
\hline \multicolumn{8}{|c|}{ PCM } \\
\hline Parameter\# & H20---H37 & Cl46---H45 & Cl46---H22 & RCPN1 & RCPN2 & RCP1 & $\mathrm{RCP} 2$ \\
\hline$\rho(\mathrm{r})$ & 0.0103 & 0.0376 & 0.0077 & 0.0069 & 0.0102 & 0.0200 & 0.0171 \\
\hline$\nabla^{2} \rho(r)$ & 0.0440 & 0.0732 & 0.0216 & 0.0244 & 0.0464 & 0.1576 & 0.1084 \\
\hline$\lambda 1$ & -0.0084 & -0.0465 & -0.0057 & -0.0056 & -0.0078 & -0.0147 & -0.0136 \\
\hline$\lambda 2$ & -0.0024 & -0.0461 & -0.0037 & 0.0014 & 0.0027 & 0.0814 & 0.0572 \\
\hline$\lambda 3$ & 0.0549 & 0.1659 & 0.0313 & 0.0287 & 0.0518 & 0.0912 & 0.0648 \\
\hline$|\lambda 1| / \lambda 3$ & 0.1530 & 0.2802 & 0.1821 & 0.1951 & 0.1505 & 0.1611 & 0.2098 \\
\hline Distances $(\AA)$ & 2.164 & 2.080 & 2.944 & & & & \\
\hline
\end{tabular}

\#Parameters in a.u.

A new $\mathrm{H}$ bond with different involved atoms is observed in both media's free base and cationic species.

Thus, each $\mathrm{C} 4-\mathrm{H} 20 \cdots \mathrm{H} 37$ and $\mathrm{N} 3-\mathrm{H} 45 \cdots \mathrm{H} 22$ interaction of the free base and cationic species, respectively, form a new RCPN1 while the RCPs of R1 (3-methoxyphenyl) and R2 (cyclohexanol) rings are named RCP1 and RCP2, respectively. In the hydrochloride species, three different interactions are observed (C15-H37 $\cdots \mathrm{C} 12, \mathrm{C} 6-\mathrm{H} 22 \cdots \mathrm{Cl} 46$ and N3-H45 $\cdots \mathrm{Cl} 46)$ in both media which one of them change in the solution. The molecular graphics of different interactions for the three tramadol species in the gas phase using the B3LYP/6-31G* method 
are shown in Figure 8. The topological properties of R1 rings in the free base, cationic, and hydrochloride species are higher than the other ones (BCPs and RCPN1). Note that the distances between two involved atoms in $\mathrm{H}$ bonds are shorter in gas phase than in aqueous solution due to the hydration, except for the $\mathrm{C} 4-\mathrm{H} 20 \cdots \mathrm{H} 37$ interaction of hydrochloride form in a solution that presents a shorter distance different from that observed in the gas phase (C15$\mathrm{H} 37 \cdots \mathrm{C} 12$ ). Thus, these studies show that the hydrochloride form in both media is the most stable species due to the three interactions that confer to its higher stability.

\subsection{Frontier orbitals and global descriptors.}

The low stability evidenced by NBO calculations for the cationic species of tramadol in aqueous solution is probably related to its most negative solvation energy value, while the hydrochloride species in this medium is the most stable in agreement with the studies observed from AIM calculations. Hence, it is impossible to understand why the hydrochloride species is a cationic one in this medium when its form shows high stability in the solution. Perhaps, an explanation could be obtained from frontier orbitals with the predictions of reactivities of three tramadol species in both media by using gap values, as suggested by Paar and Pearson [46] and, also with the predictions of its behaviors in both media $[9,15,18-23]$.

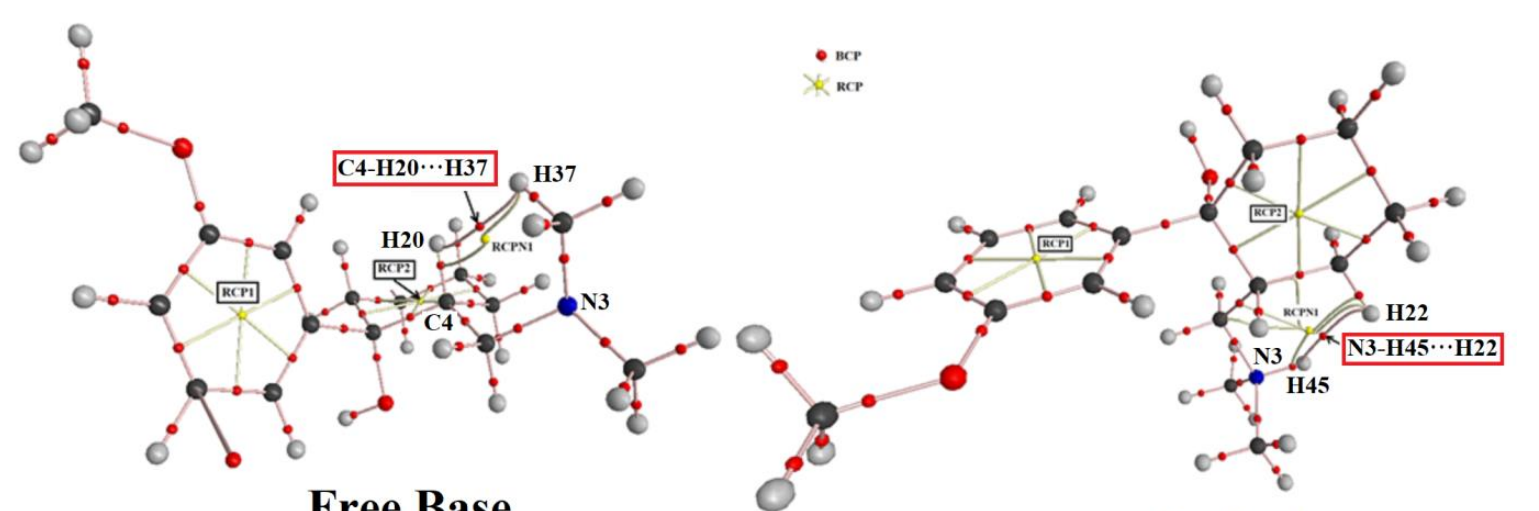

Free Base

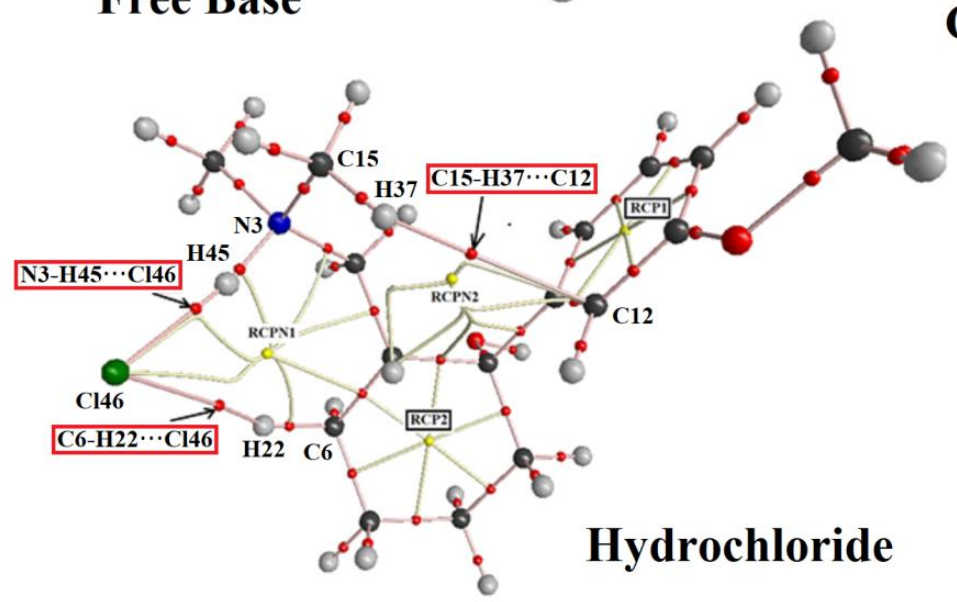

Figure 8. Molecular graphics of three species of tramadol in the gas phase showing their $\mathrm{H}$ bonds interactions by using the B3LYP/6-31G* method.

Thus, HOMO, LUMO, energy gaps and chemical potential $(\mu)$, electronegativity $(\chi)$, global hardness $(\eta)$, global softness $(S)$, global electrophilicity index $(\omega)$ and global nucleophilicity index $(E)$ descriptors for the three species of tramadol in both media by using the B3LYP/6-31G* method are presented in Table 10 together with the corresponding equations $[9,15,18-23]$. 
Table 10. Frontier molecular HOMO and LUMO orbitals, gap and chemical potential $(\mu)$, electronegativity $(\chi)$, global hardness $(\eta)$, global softness $(S)$, global electrophilicity index $(\omega)$ and global nucleophilicity index $(E)$ descriptors for the three species of Tramadol in the gas phase and aqueous solution by using the B3LYP/6-31G* level of theory.

\begin{tabular}{c|l|l|l|l|l|l}
\hline \multicolumn{7}{c}{ Gas Phase } \\
\hline \multirow{2}{*}{$\begin{array}{l}\text { Orbital } \\
(\mathrm{eV})\end{array}$} & \multicolumn{7}{c}{ B3LYP/6-31G*Method } \\
\cline { 2 - 7 } & Free base & Cationic & Hydrochloride & Free base & Cationic & Hydrochloride \\
\hline HOMO & -5.4201 & -8.4813 & -5.5243 & -5.5398 & -8.5026 & -4.7987 \\
\hline LUMO & -0.0057 & -3.0746 & -0.4910 & -0.0245 & -3.1777 & -0.6282 \\
\hline GAP & 5.4144 & 5.4067 & 5.0332 & 5.5152 & 5.3250 & 4.1705 \\
\hline \multicolumn{7}{c}{ Descriptors } \\
\hline$(\mathrm{eV})$ & Free base & Cationic & Hydrochloride & Free base & Cationic & Hydrochloride \\
\hline$\chi$ & -2.7072 & -2.7034 & -2.5166 & -2.7576 & -2.6625 & -2.0853 \\
\hline$\mu$ & -2.7129 & -5.7780 & -3.0077 & -2.7822 & -5.8402 & -2.7134 \\
\hline$\eta$ & 2.7072 & 2.7034 & 2.5166 & 2.7576 & 2.6625 & 2.0853 \\
\hline$S$ & 0.1847 & 0.1850 & 0.1987 & 0.1813 & 0.1878 & 0.2398 \\
\hline$\omega$ & 1.3593 & 6.1747 & 1.7972 & 1.4035 & 6.4052 & 1.7654 \\
\hline E & -7.344 & -15.620 & -7.569 & -7.672 & -15.549 & -5.658 \\
\hline
\end{tabular}

a This work. $\chi=-[\mathrm{E}(\mathrm{LUMO})-\mathrm{E}(\mathrm{HOMO})] / 2 ; \mu=[\mathrm{E}(\mathrm{LUMO})+\mathrm{E}(\mathrm{HOMO})] / 2 ; \eta=[\mathrm{E}(\mathrm{LUMO})-\mathrm{E}(\mathrm{HOMO})] / 2 ;$ $S=1 / 2 \eta ; \omega=\mu^{2} / 2 \eta ; E=\mu x \eta$

The low gap value $(4.1705 \mathrm{eV})$ of the hydrochloride species in solution reveals that this is the most reactive species in solution because its form has less negative Еномо $(-4.7987 \mathrm{eV})$, as compared with the free base and cationic species. However, despite in the gas phase, the free base has less negative Еномо $(-5.4201 \mathrm{eV})$; the hydrochloride form is also the most reactive species in this medium. Suppose now the hydrochloride forms of tramadol and antiviral amantadine are compared. In that case, it is observed that the species of an antiviral agent is most reactive $(\mathrm{Egap}=4.1116 \mathrm{eV})$ than the corresponding to tramadol despite its most negative Еномо (-6.4736 eV) [23]. The cationic species of tramadol in both media are less reactive than the hydrochloride ones, probably due to the higher hydration, most negative solvation energy, and the high electrophilicity and nucleophilicity indexes predicted for this species in both media, as was also observed in the cationic species de amantadine [23]. These studies have evidenced that the hydrochloride species in both media are the most reactive in the two media while the free base species have higher gap values and, for these reasons, they are the less reactive in both media. Energetically, the hydrochloride species is the most stable one in solution due to higher stabilization E, as observed from NBO studies, while the AIM analyses for this species evidence higher number of interactions in solution, but one of these interactions change the character from covalent in the gas phase to ionic in solution, justifying this way the higher reactivity observed for this species in solution. Thus, the hydrochloride species is present in solution as cationic ones because the covalent character of the H45-Cl46 bond slightly changes to ionic (N3-H45 ‥ Cl46) in this medium, as revealed by bond orders studies. In the hydrochloride species of antiviral amantadine, a similar resulted was observed [23].

\subsection{Vibrational study.}

Optimizations of tramadol species in both media using hybrid B3LYP/6-31G* calculations have shown $C_{1}$ symmetries for the three forms. The numbers of normal vibration modes expected for a free base, cationic, and hydrochloride forms of tramadol are 126, 129, and 132. All modes present activity in both infrared and Raman spectra. Experimental Attenuated Total Reflectance Infrared (ATR-IR) and Raman spectra of hydrochloride form of tramadol available from the literature can be seen in Figures 9 and 10 compared with the corresponding predicted for the three species by using the B3LYP/6-31G* method [48]. Better 
correlations were obtained when the Raman spectra were corrected from activities to intensities using well-known equations $[39,40]$. The harmonic force fields for those three species were calculated using the scaled quantum mechanical force field (SQMFF) methodology using normal internal coordinates and the Molvib program [27-29].

Scaling factors were employed in this procedure together with potential energy distribution (PED) contributions $\geq 10 \%$ [28]. In Table 11 are presented observed and calculated wavenumbers for the three species of tramadol. Comparing and analyzing all spectraall spectra exhaustively, we observed that the intense IR band predicted the hydrochloride species at $1944 \mathrm{~cm}-1$ using B3LYP/6-31G* calculations observed with lower intensity in the Raman spectrum, are not observed in both experimental spectra.

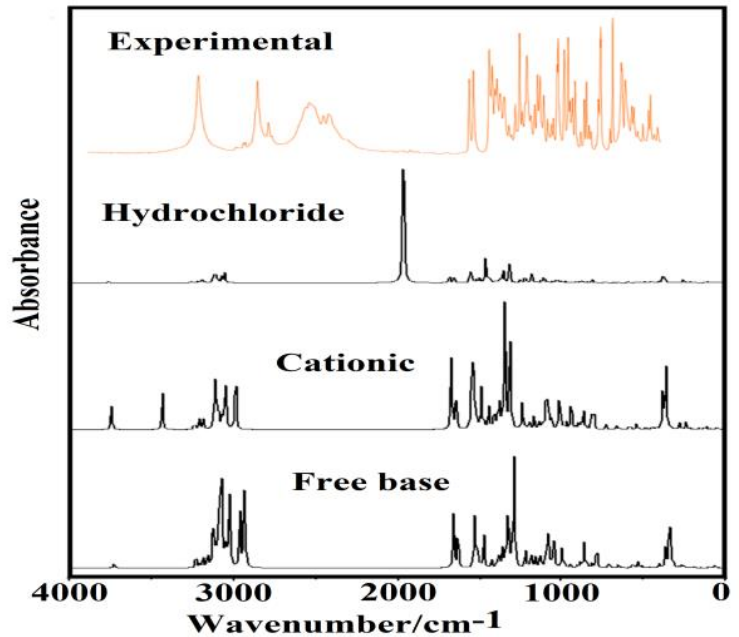

Figure 9. Experimental ATR-IR spectra of hydrochloride species of tramadol in solid phase [48] compared with the predicted for the three species in the gas phase by using the hybrid B3LYP/6-31G* method.

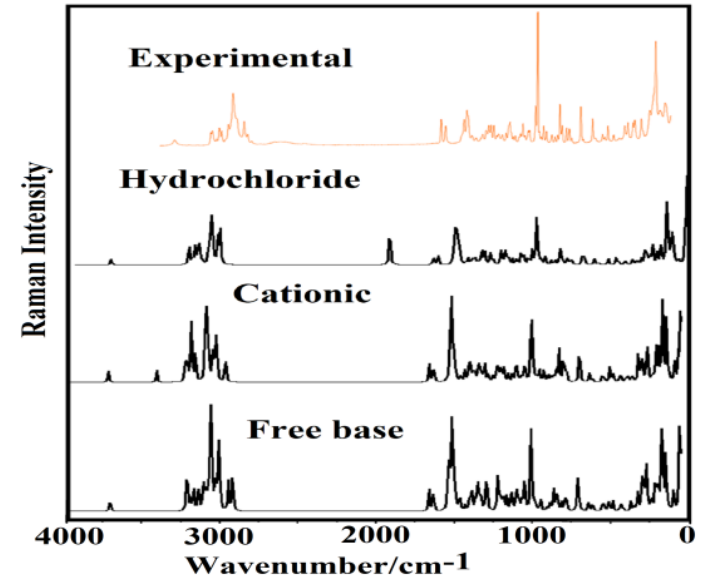

Figure 10. Experimental Raman spectra of hydrochloride species of tramadol in solid phase [48] compared with the predicted for the three species in the gas phase by using the hybrid B3LYP/6-31G* method.

Table 11. Observed and calculated wavenumbers $\left(\mathrm{cm}^{-1}\right)$ and assignments of free base, cationic, and hydrochloride species of Tramadol in the gas phase.

\begin{tabular}{|c|c|c|c|c|c|c|c|}
\hline \multirow{2}{*}{\multicolumn{2}{|c|}{ Experimental }} & \multicolumn{6}{|c|}{ B3LYP/6-31G* Method $^{\mathrm{a}}$} \\
\hline & & \multicolumn{2}{|r|}{ Hydrochhhloride } & \multicolumn{2}{|r|}{ Cationic } & \multicolumn{2}{|r|}{ Free base } \\
\hline $\mathrm{ATR}^{\mathrm{c}}$ & $\operatorname{Raman}^{\mathrm{c}}$ & SQM $^{\mathrm{b}}$ & Assignments $^{\mathrm{a}}$ & $\mathrm{SQM}^{\mathrm{b}}$ & Assignments $^{\mathrm{a}}$ & $\mathrm{SQM}^{\mathrm{b}}$ & Assignments $^{\mathrm{a}}$ \\
\hline $3403 \mathrm{sh}$ & & 3573 & vO1-H31 & 3580 & vO1-H31 & 3570 & vO1-H31 \\
\hline $3304 s$ & $3297 \mathrm{~W}$ & & & 3283 & $\mathrm{vN} 3-\mathrm{H} 45$ & & \\
\hline \multirow[t]{2}{*}{$3109 \mathrm{sh}$} & $3204 \mathrm{vw}$ & 3096 & vC18-H41 & 3102 & vC18-H41 & 3095 & vC18-H41 \\
\hline & $3153 \mathrm{vw}$ & 3091 & vC13-H33 & 3092 & vC13-H33 & 3092 & vC13-H33 \\
\hline \multirow[t]{2}{*}{$3067 \mathrm{vw}$} & $3068 \mathrm{w}$ & 3073 & vC12-H32 & 3079 & $v_{\mathrm{a}} \mathrm{CH}_{3}(\mathrm{C} 15)$ & 3074 & vC12-H32 \\
\hline & $3059 \mathrm{w}$ & 3062 & $\mathrm{v}_{\mathrm{a}} \mathrm{CH}_{3}(\mathrm{C} 15)$ & 3068 & vC12-H32 & 3054 & vC17-H40 \\
\hline \multirow[t]{4}{*}{$3052 \mathrm{vw}$} & 3049sh & 3056 & vC17-H40 & 3068 & $v_{\mathrm{a}} \mathrm{CH}_{3}(\mathrm{C} 14)$ & 3025 & $v_{\mathrm{a}} \mathrm{CH}_{3}(\mathrm{C} 19)$ \\
\hline & & 3054 & $\mathrm{v}_{\mathrm{a}} \mathrm{CH}_{3}(\mathrm{C} 14)$ & 3066 & $v \mathrm{C} 17-\mathrm{H} 40$ & 2997 & $v_{\mathrm{a}} \mathrm{CH}_{3}(\mathrm{C} 15)$ \\
\hline & & 3040 & $\mathrm{v}_{\mathrm{a}} \mathrm{CH}_{3}(\mathrm{C} 15)$ & 3065 & $\mathrm{v}_{\mathrm{a}} \mathrm{CH}_{3}(\mathrm{C} 15)$ & 2990 & $\mathrm{v}_{\mathrm{a}} \mathrm{CH}_{3}(\mathrm{C} 14)$ \\
\hline & & 3036 & $\mathrm{v}_{\mathrm{a}} \mathrm{CH}_{3}(\mathrm{C} 14)$ & 3062 & $v_{\mathrm{a}} \mathrm{CH}_{3}(\mathrm{C} 14)$ & 2980 & $v_{\mathrm{a}} \mathrm{CH}_{2}(6)$ \\
\hline $3019 \mathrm{vw}$ & $3030 \mathrm{w}$ & 3031 & $v_{\mathrm{a}} \mathrm{CH}_{3}(\mathrm{C} 19)$ & 3044 & $v_{\mathrm{a}} \mathrm{CH}_{2}(10)$ & 2971 & $\mathrm{v}_{\mathrm{a}} \mathrm{CH}_{2}(10)$ \\
\hline $3003 \mathrm{vw}$ & $3013 \mathrm{w}$ & 3013 & $v_{\mathrm{a}} \mathrm{CH}_{2}(10)$ & 3042 & $v_{\mathrm{a}} \mathrm{CH}_{3}(\mathrm{C} 19)$ & 2961 & $v_{\mathrm{a}} \mathrm{CH}_{2}(9)$ \\
\hline \multirow[t]{7}{*}{$2979 \mathrm{sh}$} & $2997 \mathrm{~W}$ & 2976 & $\mathrm{v}_{\mathrm{a}} \mathrm{CH}_{2}(6)$ & 2986 & $v_{\mathrm{s}} \mathrm{CH}_{2}(10)$ & 2954 & $v_{\mathrm{a}} \mathrm{CH}_{3}(\mathrm{C} 15), v_{\mathrm{s}} \mathrm{CH}_{3}(\mathrm{C} 15)$ \\
\hline & $2975 \mathrm{sh}$ & 2966 & $v_{\mathrm{s}} \mathrm{CH}_{2}(10)$ & 2980 & $v_{\mathrm{a}} \mathrm{CH}_{2}(9)$ & 2954 & $v_{\mathrm{a}} \mathrm{CH}_{3}(\mathrm{C} 19)$ \\
\hline & & 2965 & $\mathrm{v}_{\mathrm{a}} \mathrm{CH}_{2}(7)$ & 2977 & $v_{\mathrm{s}} \mathrm{CH}_{3}(\mathrm{C} 15)$ & 2946 & $v_{\mathrm{a}} \mathrm{CH}_{2}(7)$ \\
\hline & & 2959 & $v_{\mathrm{a}} \mathrm{CH}_{3}(\mathrm{C} 19)$ & 2976 & $v_{\mathrm{a}} \mathrm{CH}_{3}(\mathrm{C} 19)$ & 2945 & $v_{\mathrm{a}} \mathrm{CH}_{3}(\mathrm{C} 14)$ \\
\hline & 2956w & 2956 & $v_{\mathrm{s}} \mathrm{CH}_{3}(\mathrm{C} 15)$ & 2971 & $\mathrm{v}_{\mathrm{a}} \mathrm{CH}_{2}(8)$ & 2943 & $v_{\mathrm{a}} \mathrm{CH}_{2}(8)$ \\
\hline & & 2956 & $\mathrm{v}_{\mathrm{a}} \mathrm{CH}_{2}(8)$ & 2971 & $v_{\mathrm{s}} \mathrm{CH}_{3}(\mathrm{C} 14)$ & 2926 & $v_{\mathrm{s}} \mathrm{CH}_{2}(6)$ \\
\hline & & 2950 & $\mathrm{v}_{\mathrm{s}} \mathrm{CH}_{3}(\mathrm{C} 14)$ & 2963 & $\mathrm{v}_{\mathrm{a}} \mathrm{CH}_{2}(7)$ & & \\
\hline $2940 \mathrm{sh}$ & & 2949 & $\mathrm{v}_{\mathrm{a}} \mathrm{CH}_{2}(9)$ & 2952 & $v_{\mathrm{a}} \mathrm{CH}_{2}(6)$ & & \\
\hline \multirow[t]{2}{*}{$2931 \mathrm{~s}$} & $2937 \mathrm{sh}$ & 2937 & vC4-H20 & 2935 & $v_{\mathrm{s}} \mathrm{CH}_{2}(9)$ & 2918 & $\mathrm{v}_{\mathrm{s}} \mathrm{CH}_{2}(9)$ \\
\hline & $2925 \mathrm{~s}$ & 2920 & $\mathrm{v}_{\mathrm{s}} \mathrm{CH}_{2}(9)$ & 2932 & vC4-H20 & 2903 & vC4-H20 \\
\hline \multirow[t]{2}{*}{$2912 \mathrm{sh}$} & & 2917 & $\mathrm{v}_{\mathrm{s}} \mathrm{CH}_{2}(6)$ & 2924 & $v_{\mathrm{s}} \mathrm{CH}_{2}(7)$ & 2899 & $\mathrm{v}_{\mathrm{s}} \mathrm{CH}_{3}(\mathrm{C} 19)$ \\
\hline & $2904 \mathrm{sh}$ & 2908 & $v_{\mathrm{s}} \mathrm{CH}_{2}(8)$ & 2913 & $v_{\mathrm{s}} \mathrm{CH}_{3}(\mathrm{C} 19)$ & 2898 & $v_{\mathrm{s}} \mathrm{CH}_{2}(7)$ \\
\hline $2863 w$ & $2863 \mathrm{sh}$ & 2902 & $v_{\mathrm{s}} \mathrm{CH}_{3}(\mathrm{C} 19)$ & 2909 & $v_{\mathrm{s}} \mathrm{CH}_{2}(8)$ & 2890 & $v_{\mathrm{s}} \mathrm{CH}_{2}(8)$ \\
\hline
\end{tabular}


https://doi.org/10.33263/BRIAC115.1306413088

\begin{tabular}{|c|c|c|c|c|c|c|c|}
\hline \multirow{2}{*}{\multicolumn{2}{|c|}{ Experimental }} & \multicolumn{6}{|c|}{ B3LYP/6-31G* Method $^{\mathrm{a}}$} \\
\hline & & \multicolumn{2}{|r|}{ Hydrochhhloride } & \multicolumn{2}{|r|}{ Cationic } & \multicolumn{2}{|r|}{ Free base } \\
\hline \multirow[t]{3}{*}{$2842 w$} & $2854 \mathrm{~m}$ & 2901 & $v_{\mathrm{s}} \mathrm{CH}_{2}(7)$ & 2856 & $v_{\mathrm{s}} \mathrm{CH}_{2}(6)$ & 2839 & $\mathrm{v}_{\mathrm{s}} \mathrm{CH}_{2}(10)$ \\
\hline & $2836 \mathrm{w}$ & 1868 & \begin{tabular}{|l|}
$v \mathrm{~N} 3-\mathrm{H} 45$ \\
\end{tabular} & & & 2813 & $v_{\mathrm{a}} \mathrm{CH}_{3}(\mathrm{C} 15), v_{\mathrm{s}} \mathrm{CH}_{3}(\mathrm{C} 15)$ \\
\hline & $2809 w$ & & & & & 2805 & $v_{\mathrm{s}} \mathrm{CH}_{3}(\mathrm{C} 14)$ \\
\hline $1608 \mathrm{~s}$ & $1606 \mathrm{~s}$ & 1609 & $\begin{array}{l}\text { vC12-C16,vC13-C17 } \\
\text { vC11-C12,vC17-C18 }\end{array}$ & 1609 & $\begin{array}{l}\nu \mathrm{C} 12-\mathrm{C} 16, v \mathrm{C} 11-\mathrm{C} 12 \\
v \mathrm{C} 13-\mathrm{C} 17, v \mathrm{C} 17-\mathrm{C} 18\end{array}$ & 1611 & $\begin{array}{l}\nu \mathrm{C} 12-\mathrm{C} 16, v \mathrm{C} 13-\mathrm{C} 17 \\
\mathrm{vC} 11-\mathrm{C} 12, v \mathrm{C} 17-\mathrm{C} 18\end{array}$ \\
\hline $1582 \mathrm{~s}$ & $1577 \mathrm{~s}$ & 1583 & $\mathrm{vC} 16-\mathrm{C} 18 \mathrm{vC} 11-\mathrm{C} 13$ & 1583 & $\mathrm{vC} 16-\mathrm{C} 18, \mathrm{vC} 11-\mathrm{C} 13$ & 1584 & $v \mathrm{C} 16-\mathrm{C} 18, v \mathrm{C} 11-\mathrm{C} 13$ \\
\hline $1484 \mathrm{vs}$ & & 1489 & $\beta \mathrm{C} 12-\mathrm{H} 32$ & 1491 & $\beta \mathrm{C} 12-\mathrm{H} 32$ & 1489 & $\beta \mathrm{C} 17-\mathrm{H} 40, \beta \mathrm{C} 12-\mathrm{H} 32$ \\
\hline \multirow[t]{3}{*}{$1484 v s$} & & 1481 & $\delta_{\mathrm{a}} \mathrm{CH}_{3}(\mathrm{C} 15) \rho^{\prime} \mathrm{N} 3-\mathrm{H} 45$ & 1475 & $\delta_{\mathrm{a}} \mathrm{CH}_{3}(\mathrm{C} 15)$ & 1477 & $\delta_{\mathrm{a}} \mathrm{CH}_{3}(\mathrm{C} 14), \delta_{\mathrm{a}} \mathrm{CH}_{3}(\mathrm{C} 15)$ \\
\hline & & & & & & 1471 & $\delta_{\mathrm{a}} \mathrm{CH}_{3}(\mathrm{C} 19)$ \\
\hline & & 1470 & $\delta_{\mathrm{a}} \mathrm{CH}_{3}(\mathrm{C} 19)$ & 1467 & $\delta_{\mathrm{a}} \mathrm{CH}_{3}(\mathrm{C} 19)$ & 1470 & $\delta \mathrm{CH}_{2}(\mathrm{C} 10)$ \\
\hline \multirow{6}{*}{$1464 \mathrm{~s}$} & $1461 \mathrm{~s}$ & 1466 & $\delta \mathrm{CH}_{2}(\mathrm{C} 10) \delta_{\mathrm{a}} \mathrm{CH}_{3}(\mathrm{C} 14)$ & 1465 & $\delta_{\mathrm{a}} \mathrm{CH}_{3}(\mathrm{C} 14)$ & 1466 & $\delta \mathrm{CH}_{2}(\mathrm{C} 9), \delta \mathrm{CH}_{2}(\mathrm{C} 6)$ \\
\hline & & 1463 & $\delta \mathrm{CH}_{2}(\mathrm{C} 9) \delta \mathrm{CH}_{2}(\mathrm{C} 8)$ & 1463 & $\delta_{\mathrm{a}} \mathrm{CH}_{3}(\mathrm{C} 15), \delta_{\mathrm{a}} \mathrm{CH}_{3}(\mathrm{C} 14)$ & 1464 & $\delta_{\mathrm{a}} \mathrm{CH}_{3}(\mathrm{C} 15)$ \\
\hline & & 1462 & $\delta_{\mathrm{a}} \mathrm{CH}_{3}(\mathrm{C} 15)$ & 1460 & $\delta \mathrm{CH}_{2}(\mathrm{C} 8)$ & 1455 & $\delta_{\mathrm{a}} \mathrm{CH}_{3}(\mathrm{C} 19), \delta \mathrm{CH}_{2}(\mathrm{C} 10)$ \\
\hline & & 1458 & $\delta \mathrm{CH}_{2}(\mathrm{C} 10) \delta_{2} \mathrm{CH}_{3}(\mathrm{C} 15)$ & 1456 & $\delta \mathrm{CH}_{2}(\mathrm{C} 10)$ & 1454 & $\delta_{\mathrm{a}} \mathrm{CH}_{3}(\mathrm{C} 19)$ \\
\hline & & 1455 & $\delta_{\mathrm{a}} \mathrm{CH}_{3}(\mathrm{C} 19)$ & 1456 & $\delta_{\mathrm{a}} \mathrm{CH}_{3}(\mathrm{C} 19)$ & 1453 & $\delta \mathrm{CH}_{2}(\mathrm{C} 8)$ \\
\hline & & 1452 & $\delta \mathrm{CH}_{2}(\mathrm{C} 8) \delta \mathrm{CH}_{2}(\mathrm{C} 6)$ & 1450 & $\delta \mathrm{CH}_{2}(\mathrm{C} 9)$ & 1449 & $\delta_{\mathrm{a}} \mathrm{CH}_{3}(\mathrm{C} 14)$ \\
\hline \multirow[t]{4}{*}{$1449 \mathrm{~s}$} & 1446sh & 1447 & $\delta \mathrm{CH}_{2}(\mathrm{C} 9)$ & 1444 & $\delta \mathrm{CH}_{2}(\mathrm{C} 7)$ & 1447 & $\delta \mathrm{CH}_{2}(\mathrm{C} 9), \delta \mathrm{CH}_{2}(\mathrm{C} 6)$ \\
\hline & & 1444 & $\delta_{\mathrm{a}} \mathrm{CH}_{3}(\mathrm{C} 14)$ & 1441 & $\delta_{\mathrm{s}} \mathrm{CH}_{3}(\mathrm{C} 19) v \mathrm{C} 11-\mathrm{C} 12$ & 1442 & $\delta \mathrm{CH}_{2}(\mathrm{C} 7)$ \\
\hline & & 1444 & $\delta \mathrm{CH}_{2}(\mathrm{C} 7)$ & 1441 & $\delta \mathrm{CH}_{2}(\mathrm{C} 7), \delta \mathrm{CH}_{2}(\mathrm{C} 6)$ & 1441 & $\delta \mathrm{CH}_{2}(\mathrm{C} 7), \delta_{\mathrm{s}} \mathrm{CH}_{3}(\mathrm{C} 19)$ \\
\hline & & 1440 & $\begin{array}{l}\delta_{\mathrm{s}} \mathrm{CH}_{3}(\mathrm{C} 19) \\
\mathrm{vC} 11-\mathrm{C} 12 \\
\end{array}$ & 1439 & $\delta \mathrm{CH}_{2}(\mathrm{C} 6)$ & & \\
\hline $1435 \mathrm{~s}$ & $1439 \mathrm{~s}$ & 1439 & $\delta \mathrm{CH}_{2}(\mathrm{C} 10) \rho^{\prime} \mathrm{N} 3-\mathrm{H} 45$ & 1430 & $\delta_{\mathrm{s}} \mathrm{CH}_{3}(\mathrm{C} 19), \beta \mathrm{C} 18-\mathrm{H} 41$ & 1433 & $\begin{array}{l}\delta_{\mathrm{s}} \mathrm{CH}_{3}(\mathrm{C} 15) \\
\delta_{\mathrm{s}} \mathrm{CH}_{3}(\mathrm{C} 14) \\
\end{array}$ \\
\hline 1431sh & 1430sh & 1430 & $\begin{array}{l}\delta_{\mathrm{s}} \mathrm{CH}_{3}(\mathrm{C} 19) \\
\beta \mathrm{C} 18-\mathrm{H} 41 \\
\end{array}$ & 1425 & $\begin{array}{l}\delta_{\mathrm{s}} \mathrm{CH}_{3}(\mathrm{C} 14) \\
\delta_{\mathrm{s}} \mathrm{CH}_{3}(\mathrm{C} 15) \\
\end{array}$ & 1431 & $\delta_{\mathrm{s}} \mathrm{CH}_{3}(\mathrm{C} 19) \beta \mathrm{C} 18-\mathrm{H} 41$ \\
\hline \multirow[t]{2}{*}{$1416 \mathrm{~s}$} & $1411 \mathrm{w}$ & 1425 & $\rho \mathrm{N} 3-\mathrm{H} 45$ & 1413 & $\rho^{\prime} \mathrm{N} 3-\mathrm{H} 45, \rho \mathrm{N} 3-\mathrm{H} 45$ & & \\
\hline & $1401 \mathrm{sh}$ & 1406 & wagCH $_{2}(\mathrm{C} 10)$ & 1401 & $\delta_{\mathrm{s}} \mathrm{CH}_{3}(\mathrm{C} 15)$ & 1407 & $\delta_{\mathrm{s}} \mathrm{CH}_{3}(\mathrm{C} 15) \mathrm{wagCH}_{2}(\mathrm{C} 10)$ \\
\hline \multirow[t]{5}{*}{$1389 \mathrm{~m}$} & $1389 \mathrm{sh}$ & 1394 & $\delta_{\mathrm{S}} \mathrm{CH}_{3}(\mathrm{C} 14)$ & 1396 & $\delta_{\mathrm{s}} \mathrm{CH}_{3}(\mathrm{C} 14)$ & 1399 & $\delta_{\mathrm{s}} \mathrm{CH}_{3}(\mathrm{C} 14)$ \\
\hline & & 1390 & wagCH $(\mathrm{C} 6)$ & 1386 & wagCH $_{2}(\mathrm{C} 8)$ & 1377 & $\mathrm{wagCH}_{2}(\mathrm{C} 9)$ \\
\hline & & 1390 & $\delta_{\mathrm{s}} \mathrm{CH}_{3}(\mathrm{C} 15)$ & 1376 & wagCH $_{2}(\mathrm{C} 7)$,wagCH ${ }_{2}(\mathrm{C} 8)$ & 1375 & $\mathrm{wagCH}_{2}(\mathrm{C} 8), \mathrm{wagCH}_{2}(\mathrm{C} 7)$ \\
\hline & $1383 \mathrm{w}$ & 1379 & $\operatorname{wagCH}_{2}(\mathrm{C} 8)$ & 1372 & $\operatorname{wagCH}_{2}(\mathrm{C} 9), \mathrm{wagCH}_{2}(\mathrm{C} 10)$ & 1368 & $\operatorname{wagCH}_{2}(\mathrm{C} 7)$ \\
\hline & & 1372 & $\mathrm{wagCH}_{2}(\mathrm{C} 9)$ & 1372 & wagCH ${ }_{2}(\mathrm{C} 6) \rho^{\prime} \mathrm{C} 4-\mathrm{H} 20$ & 1362 & wagCH $(\mathrm{C} 8)$ \\
\hline $1361 \mathrm{w}$ & & 1363 & wagCH $($ C7) & 1363 & wagCH $2(\mathrm{C} 7)$ & & \\
\hline $1342 \mathrm{w}$ & $1342 \mathrm{w}$ & 1338 & $\rho \mathrm{CH}_{2}(\mathrm{C} 10), \rho \mathrm{C} 4-\mathrm{H} 20$ & 1332 & $\rho \mathrm{C} 4-\mathrm{H} 20$ & 1341 & $\rho \mathrm{CH}_{2}(\mathrm{C} 10)$ \\
\hline $1319 \mathrm{~m}$ & $1318 \mathrm{w}$ & 1322 & vC13-C17,vC12-C16 & 1322 & $v \mathrm{C} 13-\mathrm{C} 17$ & 1324 & $\rho \mathrm{C} 4-\mathrm{H} 20$ \\
\hline & & 1316 & $\rho^{\prime} \mathrm{C} 4-\mathrm{H} 20$ & 1318 & $\rho \mathrm{C} 4-\mathrm{H} 20$ & 1319 & $\mathrm{vC} 13-\mathrm{C} 17$ \\
\hline & & 1311 & $\rho \mathrm{CH}_{2}(\mathrm{C} 7), \rho \mathrm{CH}_{2}(\mathrm{C} 6)$ & 1306 & $\rho \mathrm{CH}_{2}(\mathrm{C} 7)$ & 1306 & $\rho \mathrm{CH}_{2}(\mathrm{C} 7)$ \\
\hline & $1301 \mathrm{~m}$ & 1300 & $\rho \mathrm{CH}_{2}(\mathrm{C} 10)$ & 1298 & vC16-O2 & 1294 & $\mathrm{vC} 16-\mathrm{O} 2, \beta \mathrm{C} 12-\mathrm{H} 32$ \\
\hline $1293 \mathrm{vs}$ & $1287 \mathrm{~m}$ & 1293 & $\rho \mathrm{CH}_{2}(\mathrm{C} 10)$ & 1288 & $\rho \mathrm{CH}_{2}(\mathrm{C} 10)$ & 1292 & $\rho^{\prime} \mathrm{C} 4-\mathrm{H} 20$ \\
\hline $1276 \mathrm{w}$ & $1271 \mathrm{~m}$ & & & & & 1274 & $\rho^{\prime} \mathrm{CH}_{3}(\mathrm{C} 14), v \mathrm{~N} 3-\mathrm{C} 10$ \\
\hline $1258 \mathrm{sh}$ & $1253 \mathrm{sh}$ & 1263 & $\rho \mathrm{C} 4-\mathrm{H} 20, \rho \mathrm{CH}_{2}(\mathrm{C} 9)$ & 1265 & $\rho \mathrm{CH}_{2}(\mathrm{C} 9), \rho \mathrm{CH}_{2}(\mathrm{C} 6)$ & 1260 & $\rho \mathrm{CH}_{2}(\mathrm{C} 9), \rho \mathrm{CH}_{2}(\mathrm{C} 6)$ \\
\hline $1247 \mathrm{~s}$ & $1242 \mathrm{w}$ & 1259 & vC16-O2 & 1265 & vC16-O2 & 1255 & vC16-O2 \\
\hline & & 1244 & $\rho^{\prime} \mathrm{CH}_{3}(\mathrm{C} 14)$ & 1240 & $\rho \mathrm{CH}_{2}(\mathrm{C} 8)$ & 1243 & $\rho \mathrm{CH}_{2}(\mathrm{C} 8)$ \\
\hline $1223 \mathrm{w}$ & $1235 \mathrm{sh}$ & 1237 & $\rho \mathrm{CH}_{2}(\mathrm{C} 8) \rho^{\prime} \mathrm{CH}_{3}(\mathrm{C} 15)$ & 1220 & $\rho^{\prime} \mathrm{CH}_{3}(\mathrm{C} 15), \rho^{\prime} \mathrm{CH}_{3}(\mathrm{C} 14)$ & & \\
\hline $1199 \mathrm{~m}$ & $1218 \mathrm{w}$ & 1199 & $8 \mathrm{C} 5 \mathrm{O} 1 \mathrm{H} 31$ & 1195 & $8 \mathrm{C} 5 \mathrm{O} 1 \mathrm{H} 31$ & 1193 & $\rho \mathrm{CH}_{2}(\mathrm{C} 9)$ \\
\hline $1181 \mathrm{~s}$ & $1192 \mathrm{w}$ & 1190 & $\rho \mathrm{CH}_{3}(\mathrm{C} 19)$ & 1189 & $\rho \mathrm{CH}_{3}(\mathrm{C} 19)$ & 1190 & $\rho \mathrm{CH}_{3}(\mathrm{C} 19)$ \\
\hline $1166 \mathrm{~s}$ & $1173 \mathrm{sh}$ & 1174 & $\beta \mathrm{C} 17-\mathrm{H} 40, \beta \mathrm{C} 13-\mathrm{H} 33$ & 1176 & $\beta \mathrm{C} 17-\mathrm{H} 40, \beta \mathrm{C} 13-\mathrm{H} 33$ & 1176 & $\delta \mathrm{C} 5 \mathrm{O} 1 \mathrm{H} 31$ \\
\hline & & 1173 & $\rho \mathrm{CH}_{3}(\mathrm{C} 14) \rho \mathrm{CH}_{3}(\mathrm{C} 15)$ & 1174 & $\rho \mathrm{CH}_{2}(\mathrm{C} 9)$ & 1173 & $\beta \mathrm{C} 13-\mathrm{H} 33$ \\
\hline & $1168 \mathrm{~s}$ & 1162 & vC5-C11 & 1158 & vC5-C11 & 1165 & $\rho \mathrm{CH}_{3}(\mathrm{C} 14), \rho \mathrm{CH}_{3}(\mathrm{C} 15)$ \\
\hline $1140 \mathrm{~m}$ & 1160sh & 1154 & $\rho^{\prime} \mathrm{CH}_{3}(\mathrm{C} 19)$ & 1151 & $\rho^{\prime} \mathrm{CH}_{3}(\mathrm{C} 19)$ & 1155 & $v \mathrm{C} 5-\mathrm{C} 11$ \\
\hline & $1148 w$ & 1154 & vC5-C11 & 1146 & $\rho^{\prime} \mathrm{CH}_{3}(\mathrm{C} 15)$ & 1154 & $\rho^{\prime} \mathrm{CH}_{3}(\mathrm{C} 19)$ \\
\hline $1118 \mathrm{w}$ & $1134 \mathrm{w}$ & 1126 & $\rho \mathrm{CH}_{2}(\mathrm{C} 8)$ & 1120 & $\rho \mathrm{CH}_{2}(\mathrm{C} 8)$ & 1129 & $\rho \mathrm{CH}_{2}(\mathrm{C} 6), \rho \mathrm{CH}_{2}(\mathrm{C} 9)$ \\
\hline $1112 \mathrm{sh}$ & $1109 w$ & 1102 & $\mathrm{vC} 13-\mathrm{C} 17$ & & & 1105 & $\rho \mathrm{CH}_{3}(\mathrm{C} 14), \rho \mathrm{CH}_{3}(\mathrm{C} 15)$ \\
\hline & $1101 \mathrm{sh}$ & & & 1099 & vC13-C17,vC17-C18 & 1099 & vC17-C18 \\
\hline $1092 \mathrm{w}$ & $1087 \mathrm{~s}$ & 1085 & $v \mathrm{C} 5-\mathrm{O} 1$ & 1083 & $v \mathrm{C} 5-\mathrm{O} 1$ & 1083 & $v \mathrm{C} 5-\mathrm{O} 1$ \\
\hline $1077 \mathrm{w}$ & $1073 w$ & 1071 & $v \mathrm{C} 4-\mathrm{C} 10, v \mathrm{C} 4-\mathrm{C} 6$ & 1070 & $v \mathrm{C} 4-\mathrm{C} 10$ & 1071 & $v \mathrm{C} 4-\mathrm{C} 10$ \\
\hline $1056 \mathrm{~s}$ & $1053 \mathrm{~m}$ & 1062 & vC7-C9,vC6-C8 & 1060 & $v \mathrm{C} 7-\mathrm{C} 9, \mathrm{v} \mathrm{C} 5-\mathrm{C} 7$ & 1060 & $v \mathrm{C} 7-\mathrm{C} 9$ \\
\hline $1056 \mathrm{~s}$ & $1053 \mathrm{~m}$ & 1058 & $\rho \mathrm{CH}_{3}(\mathrm{C} 14) \rho \mathrm{CH}_{3}(\mathrm{C} 15)$ & & & 1054 & vC19-O2 \\
\hline $1048 \mathrm{vs}$ & $1044 \mathrm{~m}$ & 1053 & vC19-O2 & 1045 & vC19-O2 & 1049 & $v \mathrm{C} 4-\mathrm{C} 10, v \mathrm{C} 6-\mathrm{C} 8$ \\
\hline $1048 \mathrm{vs}$ & $1044 \mathrm{~m}$ & 1046 & vC4-C10 & 1036 & $\rho \mathrm{CH}_{3}(\mathrm{C} 14)$ & 1040 & $\begin{array}{l}\rho^{\prime} \mathrm{CH}_{3}(\mathrm{C} 14), v \mathrm{~N} 3-\mathrm{C} 15 \\
\rho^{\prime} \mathrm{CH}_{3}(\mathrm{C} 15), v \mathrm{~N} 3-\mathrm{C} 14\end{array}$ \\
\hline $1013 \mathrm{~s}$ & $1006 \mathrm{vs}$ & 1023 & vC5-C4,vC5-C7 & 1030 & $\rho \mathrm{CH}_{3}(\mathrm{C} 15)$ & 1021 & $v \mathrm{C} 5-\mathrm{C} 4, \mathrm{vC5}-\mathrm{C} 7$ \\
\hline $987 \mathrm{vs}$ & 991vs & 1002 & vN3-C14,vN3-C15 & 1014 & $v \mathrm{C} 5-\mathrm{C} 4$ & 1014 & vN3-C10 \\
\hline $987 \mathrm{vs}$ & 982sh & 992 & $\beta \mathrm{R}_{1}(\mathrm{~A} 1)$ & 991 & $\beta R_{1}(\mathrm{~A} 1)$ & 993 & $\beta \mathrm{R}_{1}(\mathrm{~A} 1)$ \\
\hline & & & & 974 & $\gamma \mathrm{C} 17-\mathrm{H} 40$ & & \\
\hline $976 \mathrm{~m}$ & $970 w$ & 976 & $v \mathrm{~N} 3-\mathrm{C} 10, \beta \mathrm{R}_{1}(\mathrm{~A} 2)$ & 971 & vN3-C15 & 965 & $\gamma \mathrm{C} 17-\mathrm{H} 40, \gamma \mathrm{C} 13-\mathrm{H} 33$ \\
\hline $960 \mathrm{~m}$ & & 967 & $\gamma \mathrm{C} 17-\mathrm{H} 40, \gamma \mathrm{C} 13-\mathrm{H} 33$ & 964 & vC7-C9,vC5-O1 & 964 & $v \mathrm{C} 5-\mathrm{O} 1$ \\
\hline & & 964 & $\gamma \mathrm{C} 17-\mathrm{H} 40 \mathrm{vC} 6-\mathrm{C} 8$ & 959 & vC6-C8 & 960 & $v \mathrm{C} 6-\mathrm{C} 8$ \\
\hline $943 \mathrm{~s}$ & $954 \mathrm{~s}$ & 951 & vN3-C10 & 929 & $v \mathrm{C} 5-\mathrm{O} 1$ & 930 & $v \mathrm{C} 5-\mathrm{O} 1$ \\
\hline $908 w$ & $937 \mathrm{~m}$ & 932 & $v \mathrm{C} 5-\mathrm{O} 1$ & 907 & \begin{tabular}{|l|}
$v \mathrm{~N} 3-\mathrm{C} 14$ \\
\end{tabular} & & \\
\hline & $902 \mathrm{w}$ & 899 & $\tau \mathrm{wCH}(\mathrm{C} 6)$ & 895 & vN3-C10 & 900 & $\tau \mathrm{wCH} \mathrm{H}_{2}(\mathrm{C} 6), \tau \mathrm{wCH}_{2}(\mathrm{C} 7)$ \\
\hline
\end{tabular}

https://biointerfaceresearch.com/ 


\begin{tabular}{|c|c|c|c|c|c|c|c|}
\hline \multirow{2}{*}{\multicolumn{2}{|c|}{ Experimental }} & \multicolumn{6}{|c|}{ B3LYP/6-31G* Method $^{\mathrm{a}}$} \\
\hline & & \multicolumn{2}{|r|}{ Hydrochhhloride } & \multicolumn{2}{|r|}{ Cationic } & \multicolumn{2}{|r|}{ Free base } \\
\hline $886 \mathrm{~m}$ & $882 \mathrm{w}$ & 888 & $\gamma \mathrm{C} 12-\mathrm{H} 32, \gamma \mathrm{C} 18-\mathrm{H} 41$ & 891 & $\gamma \mathrm{C} 18-\mathrm{H} 41, \gamma \mathrm{C} 13-\mathrm{H} 33$ & 885 & $\gamma \mathrm{C} 18-\mathrm{H} 41$ \\
\hline $872 \mathrm{~s}$ & & 881 & $\gamma \mathrm{C} 12-\mathrm{H} 32$ & 874 & $\gamma \mathrm{C} 12-\mathrm{H} 32$ & 879 & $\gamma \mathrm{C} 12-\mathrm{H} 32$ \\
\hline $853 \mathrm{w}$ & $866 \mathrm{w}$ & 867 & $\tau \mathrm{wCH}_{2}(\mathrm{C} 10)$ & 844 & vC8-C9 & 852 & vN3-C15,vN3-C14 \\
\hline $842 \mathrm{w}$ & $849 \mathrm{~s}$ & 839 & vC8-C9 & 835 & $\tau \mathrm{wCH}_{2}(\mathrm{C} 9), \nu \mathrm{C} 8-\mathrm{C} 9$ & 838 & $v \mathrm{C} 8-\mathrm{C} 9$ \\
\hline $812 \mathrm{sh}$ & $837 \mathrm{~s}$ & 825 & $\beta \mathrm{R}_{3}(\mathrm{~A} 1)$ & 822 & $\tau \mathrm{wCH}_{2}(\mathrm{C} 10)$ & 823 & $\tau \mathrm{wCH}(\mathrm{C} 10) \tau \mathrm{wCH} \mathrm{CH}_{2}(\mathrm{C} 8)$ \\
\hline $798 \mathrm{~m}$ & $809 \mathrm{~m}$ & 813 & $\tau \mathrm{wCH} \mathrm{CH}_{2}(\mathrm{C} 10) \tau \mathrm{wCH} \mathrm{CH}_{2}(\mathrm{C} 8)$ & 801 & $v \mathrm{~N} 3-\mathrm{C} 15, \mathrm{vN} 3-\mathrm{C} 10$ & 820 & vN3-C15 \\
\hline $785 \mathrm{~s}$ & $792 \mathrm{~m}$ & 789 & $\gamma \mathrm{C} 18-\mathrm{H} 41$ & 794 & $\gamma \mathrm{C} 18-\mathrm{H} 41, \gamma \mathrm{C} 13-\mathrm{H} 33$ & 787 & $\gamma \mathrm{C} 18-\mathrm{H} 41 \gamma \mathrm{C} 17-\mathrm{H} 40$ \\
\hline $783 \mathrm{vs}$ & $777 \mathrm{w}$ & 772 & vC4-C6, $\tau \mathrm{wCH}_{2}(\mathrm{C} 8)$ & 764 & vC4-C6, $\tau w \mathrm{CH}_{2}(\mathrm{C} 8)$ & 770 & $v \mathrm{C} 4-\mathrm{C} 6$ \\
\hline $765 \mathrm{sh}$ & $754 \mathrm{vw}$ & 750 & $\tau \mathrm{wCH}_{2}(\mathrm{C} 7) \tau \mathrm{wCH}_{2}(\mathrm{C} 9)$ & 742 & $\begin{array}{l}\tau \mathrm{wCH}_{2}(\mathrm{C} 7), \tau \mathrm{w} \mathrm{CH}_{2}(\mathrm{C} 9) \\
\tau \mathrm{wCH}_{2}(\mathrm{C} 6) \\
\end{array}$ & 745 & $\begin{array}{ll}\tau \mathrm{wCH}_{2}(\mathrm{C} 7) \\
\tau \mathrm{wCH}_{2}(\mathrm{C} 9), \tau \mathrm{wCH} & (\mathrm{C} 6) \\
\end{array}$ \\
\hline $724 w$ & $718 \mathrm{~s}$ & 702 & $\tau \mathrm{R}_{1}(\mathrm{~A} 1)$ & 697 & $\tau \mathrm{R}_{1}(\mathrm{~A} 1)$ & 700 & $\beta \mathrm{R}_{2}(\mathrm{~A} 1), \tau \mathrm{wCH}_{2}(\mathrm{C} 6)$ \\
\hline 706vs & $703 \mathrm{vw}$ & 698 & $\gamma \mathrm{C} 11-\mathrm{C} 5$ & 691 & $\beta \mathrm{R}_{2}(\mathrm{~A} 1), \nu \mathrm{C} 5-\mathrm{C} 4$ & 697 & $\tau \mathrm{R}_{1}(\mathrm{~A} 1)$ \\
\hline $650 \mathrm{~s}$ & $644 \mathrm{~s}$ & 650 & $\beta \mathrm{R}_{2}(\mathrm{~A} 1)$ & 643 & $\beta \mathrm{R}_{2}(\mathrm{~A} 1)$ & 649 & $\beta \mathrm{R}_{2}(\mathrm{~A} 1)$ \\
\hline $625 \mathrm{~s}$ & $624 w$ & 625 & $\tau \mathrm{R}_{2}(\mathrm{~A} 1), \gamma \mathrm{C} 16-\mathrm{O} 2$ & 624 & $\gamma \mathrm{C} 16-\mathrm{O} 2$ & 624 & $\gamma \mathrm{C} 16-\mathrm{O} 2$ \\
\hline $586 \mathrm{~m}$ & $582 \mathrm{w}$ & 574 & $\delta \mathrm{C} 16 \mathrm{O} 2 \mathrm{C} 19, \beta \mathrm{C} 16-\mathrm{O} 2$ & 574 & $\delta \mathrm{C} 16 \mathrm{O} 2 \mathrm{C} 19, \beta \mathrm{C} 16-\mathrm{O} 2$ & 574 & $\delta \mathrm{C} 16 \mathrm{O} 2 \mathrm{C} 19, \beta \mathrm{C} 16-\mathrm{O} 2$ \\
\hline $572 \mathrm{~m}$ & $568 \mathrm{w}$ & 566 & $\delta \mathrm{C} 14 \mathrm{~N} 3 \mathrm{C} 10, \rho \mathrm{C} 5-\mathrm{O} 1$ & 555 & $\delta \mathrm{C} 10 \mathrm{C} 4 \mathrm{C} 5, \delta \mathrm{C} 14 \mathrm{~N} 3 \mathrm{C} 10$ & 556 & $\rho \mathrm{C} 5-\mathrm{O} 1, \delta \mathrm{C} 14 \mathrm{~N} 3 \mathrm{C} 10$ \\
\hline $551 \mathrm{w}$ & $548 \mathrm{~s}$ & 527 & $\beta \mathrm{R}_{2}(\mathrm{~A} 2)$ & 526 & $\beta \mathrm{R}_{2}(\mathrm{~A} 2)$ & 533 & $\beta \mathrm{R}_{2}(\mathrm{~A} 2)$ \\
\hline $516 \mathrm{w}$ & $512 \mathrm{w}$ & 510 & $\beta \mathrm{R}_{3}(\mathrm{~A} 1)$ & 507 & $\beta \mathrm{R}_{3}(\mathrm{~A} 1)$ & 509 & $\beta \mathrm{R}_{3}(\mathrm{~A} 1)$ \\
\hline $481 \mathrm{w}$ & $477 \mathrm{w}$ & 474 & $\beta \mathrm{R}_{1}(\mathrm{~A} 2)$ & 466 & $\beta R_{1}(\mathrm{~A} 2)$ & 466 & $\beta R_{1}(\mathrm{~A} 2)$ \\
\hline $470 \mathrm{~m}$ & $465 \mathrm{vw}$ & 465 & $\tau \mathrm{R}_{3}(\mathrm{~A} 1)$ & 462 & $\tau \mathrm{R}_{3}$ (A1) & 462 & $\tau \mathrm{R}_{3}(\mathrm{~A} 1)$ \\
\hline $444 w$ & $439 \mathrm{~s}$ & 437 & $8 \mathrm{C} 14 \mathrm{~N} 3 \mathrm{C} 15$ & 440 & $\delta \mathrm{C} 15 \mathrm{~N} 3 \mathrm{C} 10$ & 453 & $\delta \mathrm{C} 14 \mathrm{~N} 3 \mathrm{C} 15$ \\
\hline $423 w$ & $420 \mathrm{~s}$ & 428 & $8 \mathrm{C} 15 \mathrm{~N} 3 \mathrm{C} 10$ & 430 & $\delta \mathrm{C} 14 \mathrm{~N} 3 \mathrm{C} 15$ & 406 & $\beta \mathrm{R}_{2}(\mathrm{~A} 2)$ \\
\hline \multirow[t]{28}{*}{ 416sh } & $389 \mathrm{~s}$ & 406 & $\delta \mathrm{C} 15 \mathrm{~N} 3 \mathrm{C} 10$ & 403 & $\delta \mathrm{C} 15 \mathrm{~N} 3 \mathrm{C} 10, \beta \mathrm{R}_{2}(\mathrm{~A} 2)$ & 390 & $8 \mathrm{C} 15 \mathrm{~N} 3 \mathrm{C} 10$ \\
\hline & $377 \mathrm{~s}$ & 384 & $\delta \mathrm{C} 14 \mathrm{~N} 3 \mathrm{C} 10$ & 366 & 8C7C5C11 & 370 & $8 \mathrm{C} 7 \mathrm{C} 5 \mathrm{C} 11$ \\
\hline & 366sh & 360 & $\delta \mathrm{C} 10 \mathrm{C} 4 \mathrm{C} 6, \delta \mathrm{C} 7 \mathrm{C} 5 \mathrm{C} 11$ & 355 & $\delta \mathrm{C} 10 \mathrm{C} 4 \mathrm{C} 6$ & 350 & $8 \mathrm{C} 10 \mathrm{C} 4 \mathrm{C} 6$ \\
\hline & $337 \mathrm{~s}$ & 337 & $\tau \mathrm{R}_{1}(\mathrm{~A} 2)$ & 328 & $\rho^{\prime} \mathrm{C} 5-\mathrm{O} 1$ & 331 & $\rho^{\prime} \mathrm{C} 5-\mathrm{O} 1$ \\
\hline & $325 \mathrm{sh}$ & 332 & $\rho^{\prime} \mathrm{C} 5-\mathrm{O} 1$ & 322 & $\tau \mathrm{R}_{1}(\mathrm{~A} 2)$ & 326 & $\delta \mathrm{C} 14 \mathrm{~N} 3 \mathrm{C} 10$ \\
\hline & 320sh & 315 & $\tau \mathrm{O} 1-\mathrm{H} 31$ & 311 & $\tau \mathrm{O} 1-\mathrm{H} 31$ & 310 & $\tau \mathrm{O} 1-\mathrm{H} 31$ \\
\hline & $308 \mathrm{vw}$ & 296 & $\beta R_{3}(\mathrm{~A} 2)$ & 288 & $\beta R_{3}(\mathrm{~A} 2)$ & 293 & $\beta R_{3}(\mathrm{~A} 2)$ \\
\hline & $280 \mathrm{~s}$ & 277 & $\rho \mathrm{C} 5-\mathrm{O} 1$ & 268 & $\rho \mathrm{C} 5-\mathrm{O} 1$ & 269 & $\rho \mathrm{C} 5-\mathrm{O} 1$ \\
\hline & $256 \mathrm{sh}$ & 257 & $\tau \mathrm{R}_{2}(\mathrm{~A} 1), \tau \mathrm{wCH}(\mathrm{C} 19)$ & & & 258 & $\tau \mathrm{wCH}_{3}(\mathrm{C} 19)$ \\
\hline & $256 \mathrm{sh}$ & & & 253 & $\tau \mathrm{R}_{2}(\mathrm{~A} 1), \tau \mathrm{R}_{3}(\mathrm{~A} 1)$ & 250 & $\tau \mathrm{wCH}_{3}(\mathrm{C} 14), \delta \mathrm{C} 16 \mathrm{O} 2 \mathrm{C} 19$ \\
\hline & 244vs & 243 & $\delta \mathrm{C} 4 \mathrm{C} 5 \mathrm{C} 11$ & 244 & $\tau \mathrm{R}_{2}(\mathrm{~A} 1), \tau \mathrm{wCH} \mathrm{H}_{3}(\mathrm{C} 19)$ & 235 & $\tau \mathrm{wCH}_{3}(\mathrm{C} 14)$ \\
\hline & $237 \mathrm{sh}$ & 238 & $8 \mathrm{C} 10 \mathrm{C} 4 \mathrm{C} 5$ & & & 231 & $\tau \mathrm{wCH}_{3}(\mathrm{C} 14)$ \\
\hline & $225 \mathrm{sh}$ & 227 & vH45-Cl46 & 228 & $\delta \mathrm{C} 4 \mathrm{C} 10 \mathrm{~N} 3, \tau \mathrm{R}_{1}(\mathrm{~A} 1)$ & 224 & $\tau \mathrm{wCH}_{3}(\mathrm{C} 15)$ \\
\hline & $218 w$ & 211 & $\tau \mathrm{R}_{3}(\mathrm{~A} 2)$ & 215 & $\tau \mathrm{wCH}_{3}(\mathrm{C} 14), \tau \mathrm{wCH}_{3}(\mathrm{C} 15)$ & 199 & $\tau \mathrm{R}_{2}(\mathrm{~A} 1)$ \\
\hline & 191sh & 199 & $\tau \mathrm{wCH}_{3}(\mathrm{C} 19)$ & 193 & $\tau \mathrm{R}_{3}(\mathrm{~A} 2)$ & 194 & $\tau \mathrm{R}_{3}(\mathrm{~A} 2), \tau \mathrm{R}_{2}(\mathrm{~A} 2)$ \\
\hline & $186 \mathrm{~s}$ & 193 & $\tau \mathrm{wCH}_{3}(\mathrm{C} 15)$ & 192 & $\tau \mathrm{R}_{2}(\mathrm{~A} 1), \tau \mathrm{wCH} \mathrm{H}_{3}(\mathrm{C} 19)$ & & \\
\hline & 174sh & 182 & $\tau \mathrm{wCH}_{3}(\mathrm{C} 14)$ & 184 & $\tau \mathrm{R}_{2}(\mathrm{~A} 2)$ & & \\
\hline & $165 \mathrm{sh}$ & 166 & $\beta \mathrm{C} 11-\mathrm{C} 5, \delta \mathrm{C} 4 \mathrm{C} 10 \mathrm{~N} 3$ & 146 & $\beta C 11-\mathrm{C} 5$ & 155 & $\beta C 11-\mathrm{C} 5$ \\
\hline & & 118 & $\tau \mathrm{wCH}_{3}(\mathrm{C} 15)$ & 120 & $\delta \mathrm{C} 4 \mathrm{C} 10 \mathrm{~N} 3$ & 113 & $8 \mathrm{C} 10 \mathrm{C} 4 \mathrm{C} 5, \delta \mathrm{C} 4 \mathrm{C} 10 \mathrm{~N} 3$ \\
\hline & & 107 & $\tau \mathrm{N} 3-\mathrm{H} 45$ & & & & \\
\hline & & 97 & $\tau \mathrm{O} 2-\mathrm{C} 16, \tau \mathrm{C} 10-\mathrm{C} 4$ & 99 & $\tau \mathrm{O} 2-\mathrm{C} 16, \tau \mathrm{w} \mathrm{CH}_{3}(\mathrm{C} 19)$ & 101 & $\tau \mathrm{O} 2-\mathrm{C} 16, \tau \mathrm{w} \mathrm{CH}_{3}(\mathrm{C} 19)$ \\
\hline & & 90 & $\tau \mathrm{R}_{2}(\mathrm{~A} 2)$ & & & & \\
\hline & & & & 76 & $8 \mathrm{C} 4 \mathrm{C} 5 \mathrm{C} 11$ & 75 & $8 \mathrm{C} 4 \mathrm{C} 5 \mathrm{C} 11$ \\
\hline & & 69 & $\tau \mathrm{O} 2-\mathrm{C} 16$ & 72 & $\tau \mathrm{O} 2-\mathrm{C} 16$ & 68 & $\tau \mathrm{O} 2-\mathrm{C} 16$ \\
\hline & & 59 & $\delta \mathrm{N} 3 \mathrm{H} 45 \mathrm{Cl} 46$ & 45 & $\tau \mathrm{N} 3-\mathrm{C} 10, \gamma \mathrm{C} 11-\mathrm{C} 5$ & 45 & $\tau \mathrm{C} 5-\mathrm{C} 11, \gamma \mathrm{C} 11-\mathrm{C} 5$ \\
\hline & & 34 & $\tau \mathrm{C} 5-\mathrm{C} 11$ & 37 & $\tau \mathrm{C} 10-\mathrm{C} 4$ & 32 & $\tau \mathrm{N} 3-\mathrm{C} 10$ \\
\hline & & 31 & $\tau \mathrm{N} 3-\mathrm{C} 10$ & 27 & $\tau \mathrm{C} 5-\mathrm{C} 11$ & 26 & $\tau \mathrm{C} 10-\mathrm{C} 4$ \\
\hline & & 16 & $\tau \mathrm{C} 10-\mathrm{C} 4, \tau \mathrm{N} 3-\mathrm{C} 10$ & & & & \\
\hline
\end{tabular}

Abbreviations: $v$, stretching; $\beta$, deformation in the plane; $\gamma$, deformation out of plane; wag, wagging; $\tau$, torsion; $\beta_{\mathrm{R}}$, deformation ring $\tau_{\mathrm{R}}$, torsion ring; $\rho$, rocking; $\tau \mathrm{w}$, twisting; $\delta$, deformation; a, antisymmetric; s, symmetric; $\left(\mathrm{A}_{1}\right)$, Ring 1; $\left(\mathrm{A}_{2}\right)$, Ring $2 .{ }^{\mathrm{a}}$ This work, ${ }^{\mathrm{b}}$ From scaled quantum mechanics force field, ${ }^{\mathrm{c}}$ From Ref [48].

For these reasons, the hydrochloride form of tramadol is a cationic one in the solid phase, in agreement with all studied hydrochloride species of different pharmacological drugs by using vibrational spectroscopy [3-5,7,9-23]. That strong IR band calculated at $1944 \mathrm{~cm}^{-1}$ is predicted by SQM calculations at $1868 \mathrm{~cm}^{-1}$. I $\mathrm{t}$ is assigned to the $v \mathrm{~N} 3-\mathrm{H} 45$ stretching mode of hydrochloride form.

Probably, the numerous IR bands observed in the $1700-400 \mathrm{~cm}^{-1}$ region in the ATR spectrum could indicate the presence of a free base in the solid phase. Obviously, the differences observed between experimental and theoretical spectra can be attributed to the calculations. These were performed in the gas phase, where the packing forces existent in the 
solid phase were not considered. Thus, the group of bands between 2758 and $2368 \mathrm{~cm}^{-1}$, centered in the IR spectrum at $2605 \mathrm{~cm}^{-1}$ and $2621 \mathrm{~cm}^{-1}$ in the Raman one, could be associated with dimeric species not considered in this work. Brief discussions of some assignments are presented below.

\subsubsection{Band Assignments.}

$4000-2000 \mathrm{~cm}^{-1}$ region. In this region are expected characteristic bands related to stretching modes of $\mathrm{OH}, \mathrm{NH}, \mathrm{CH}_{3}, \mathrm{CH}_{2}$, and aromatic and aliphatic $\mathrm{C}-\mathrm{H}$ groups [3-5,7,9-23]. The $\mathrm{OH}$ stretching modes in the three species are predicted in the same regions; hence, the shoulder at $3403 \mathrm{~cm}^{-1}$ is assigned to these stretching modes. The strong IR band at $3304 \mathrm{~cm}^{-1}$ is quickly assigned to $\mathrm{NH}$ stretching of cationic species. The aromatic $\mathrm{CH}$ stretching mode is assigned as predicted by calculations between 3102 and $3054 \mathrm{~cm}^{-1}$, while the only aliphatic mode in the three species is assigned between 2937 and $2903 \mathrm{~cm}^{-1}$. The antisymmetric and symmetric modes of $\mathrm{CH}_{3}$ groups are assigned from $3068 \mathrm{~cm}^{-1}$ up to $2805 \mathrm{~cm}^{-1}$, while these modes for $\mathrm{CH}_{2}$ groups between 3044 and $2839 \mathrm{~cm}^{-1}$, as detailed in Table 11 and, as observed in similar compounds [3-5,7,9-23]. The group of bands between 2758 and $2368 \mathrm{~cm}^{-1}$ can be attributed to dimeric hydrochloride species, as reported for anti-hypertensive agent tolazoline hydrochloride $[18,19]$.

$1800-1000 \mathrm{~cm}^{-1}$ region. Characteristic bands associated with deformation, wagging, and rocking modes of $\mathrm{CH}_{2}, \mathrm{CH}_{3}, \mathrm{OH}, \mathrm{NH}$ and $\mathrm{C}-\mathrm{H}$ groups and $\mathrm{C}-\mathrm{C}, \mathrm{N}-\mathrm{C}$, and $\mathrm{C}-\mathrm{O}$ stretching modes are expected in this region [3-5,7,9-23]. The strong pairs of IR/Raman band at $1608 / 1582$, and $1606 / 1577 \mathrm{~cm}^{-1}$ are assigned to $\mathrm{C}=\mathrm{C}$ stretching modes of $\mathrm{R} 1$ rings, while the very strong IR band at $1484 \mathrm{~cm}^{-1}$ is associated with in-plane $\mathrm{CH}$ deformations of three species. The three antisymmetric and symmetric $\mathrm{CH}_{3}$ deformations and $\mathrm{CH}_{2}$ deformations modes are assigned between $1481 \mathrm{~cm}^{-1}$ and $1390 \mathrm{~cm}^{-1}$, while the IR bands at 1199 and $1166 \mathrm{~cm}^{-1}$ are assigned to $\mathrm{OH}$ deformations, as predicted by SQM calculations. The strong IR band at 1416 $\mathrm{cm}^{-1}$ is assigned to N-H rocking modes of cationic and hydrochloride species, while the band of medium intensity at $1319 \mathrm{~cm}^{-1}$ and the intense IR band at $1247 \mathrm{~cm}^{-1}$ are assigned to C-C and C16-O2 stretching modes, respectively. The intense Raman band at $1087 \mathrm{~cm}^{-1}$ can be assigned to $\mathrm{C} 5-\mathrm{O} 1$ stretching modes of three tramadol species, while other $\mathrm{C}-\mathrm{C}$ stretching modes can also be assigned to IR and Raman bands between 1077 and $987 \mathrm{~cm}^{-1}$.

$1000-10 \mathrm{~cm}^{-1}$ region. In this region, the SQM calculations predict $\mathrm{C}-\mathrm{C}, \mathrm{N}-\mathrm{C}$, and $\mathrm{C}-\mathrm{O}$ stretching, $\mathrm{OH}, \mathrm{CH}_{3}$, and $\mathrm{CH}_{2}$ twisting and skeletal modes of both rings. The strong band at $783 \mathrm{~cm}^{-1}$ is assigned to C4-C6 stretching modes of the three species because the SQM calculations predict these modes between 772 and $764 \mathrm{~cm}^{-1}$ while the intense band located at $987 \mathrm{~cm}^{-1}$ is associated with one of three deformations rings $\mathrm{R} 1$ of three species ( $\left.\beta \mathrm{R}_{1}(\mathrm{~A} 1)\right)$ ). The IR at $798 \mathrm{~cm}^{-1}$ can be assigned to stretching modes of N3-C15 and N3-C10 bonds or the twisting mode of $\mathrm{CH}_{2}$ groups, while the strong Raman bands at 389, 377, and $280 \mathrm{~cm}^{-1}$ are associated with $\mathrm{C} 15 \mathrm{~N} 3 \mathrm{C} 10, \mathrm{C} 14 \mathrm{~N} 3 \mathrm{C} 10, \mathrm{C} 7 \mathrm{C} 5 \mathrm{C} 11$ deformations, and C5-O1 rocking modes.

Deformations and torsions of methoxyphenyl rings (R1 or A1) and cyclohexanol (R2 or A2) are predicted by SQM calculations in the $1000-60 \mathrm{~cm}^{-1}$ region, as was observed in species containing six members rings [3-5,7,9-23]. Note that practically in all regions, the SQM calculations predict some vibration modes' coupling, as was detailed in Table 11. 


\subsection{Force constants.}

The determinations of harmonic force fields for the three tramadol species in both media with the SQMFF methodology and Molvib program by using the B3LYP/6-31G* level of the theory have allowed computing scaled force constants for those species in the two media [27-29]. The results for the three species of tramadol in both media are presented in Table 12.

Table 12. Scaled internal force constants for the free base, cationic, and hydrochloride tramadol species in gas and aqueous solution phases using the B3LYP/6-31G* method.

\begin{tabular}{|c|c|c|c|c|c|c|}
\hline \multirow{4}{*}{$\begin{array}{l}\text { Force } \\
\text { constant }\end{array}$} & \multicolumn{6}{|c|}{ B3LYP/6-31G* method } \\
\hline & \multicolumn{6}{|c|}{ Tramadol $^{\mathrm{a}}$} \\
\hline & \multicolumn{2}{|c|}{ Free base } & \multicolumn{2}{|c|}{ Cationic } & \multicolumn{2}{|c|}{ Hydrochloride } \\
\hline & Gas & PCM & Gas & PCM & Gas & PCM \\
\hline$f(v O-H)$ & 7.13 & 7.09 & 7.17 & 7.09 & 7.14 & 7.11 \\
\hline$f(v N-H)$ & & & 5.98 & 6.03 & 2.82 & 4.78 \\
\hline$f(v C-O)_{O H}$ & 4.48 & 4.33 & 4.57 & 4.41 & 4.52 & 4.41 \\
\hline$f(\nu C-O)_{O C H}$ & 5.45 & 5.05 & 5.50 & 5.05 & 5.48 & 5.03 \\
\hline$f(v C-N)$ & 4.72 & 4.59 & 3.86 & 4.04 & 4.27 & 4.13 \\
\hline$f(\nu C-H)_{R I}$ & 5.21 & 5.23 & 5.21 & 5.23 & 5.21 & 5.23 \\
\hline$f(v C-H)_{R 2}$ & 4.66 & 4.75 & 4.76 & 4.83 & 4.76 & 4.82 \\
\hline$f(v C-C)_{R}$ & 6.45 & 6.43 & 6.43 & 6.43 & 6.43 & 6.43 \\
\hline$f\left(v \mathrm{CH}_{2}\right)$ & 4.73 & 4.73 & 4.80 & 4.81 & 4.79 & 4.80 \\
\hline$f\left(v \mathrm{CH}_{3}\right)$ & 4.75 & 4.80 & 5.02 & 5.04 & 4.96 & 5.03 \\
\hline$f\left(\delta \mathrm{CH}_{2}\right)$ & 0.75 & 0.74 & 0.74 & 0.73 & 0.75 & 0.73 \\
\hline$f\left(\delta C H_{3}\right)$ & 0.58 & 0.57 & 0.57 & 0.56 & 0.57 & 0.56 \\
\hline
\end{tabular}

The $f(v O-H)$ force constants of the three species show a decrease in solution due to the hydrations of these groups with water molecules, as also was observed in the $f(\nu C-O)_{O H}$ and $f(v \mathrm{C}-\mathrm{O})_{\text {OCH3 }}$ force constants. However, the $f(v \mathrm{~N}-\mathrm{H})$ force constants of hydrochloride species increase in solution while remains practically constant in the cationic species. In the hydrochloride form, the presence of $\mathrm{Cl}$ atom justifies that observation because the N3-H45 bond is shortened of $1.128 \AA$ in the gas phase to $1.056 \AA$ in solution while the $\mathrm{H} 45 \cdots \mathrm{Cl} 46$ bond increases from $1.778 \AA$ in the gas phase to $2.080 \AA$ in solution. The remaining force constants do not show changes in the three species or with the medium and show values approximately similar to reported for other pharmacological species [3-5,7,9-23].

\subsection{NMR study.}

The GIAO method was used to predict the ${ }^{1} \mathrm{H}$ and ${ }^{13} \mathrm{C}$ NMR chemical shifts of three species of tramadol in an aqueous solution with the hybrid B3LYP/6-31G* level of theory [47]. These results were compared with the corresponding experimental spectra available from the literature for tramadol hydrochloride solution in DMSO-d6 [24]. Comparisons between experimental and theoretical ${ }^{1} \mathrm{H}$ and ${ }^{13} \mathrm{C}$ NMR chemical shifts are presented in Tables 13 and 14 , respectively, using the RMSDs values [24].

Table 13. Observed and calculated ${ }^{1} \mathrm{H}$ chemical shifts $(\delta$ in $\mathrm{ppm})$ for the three Tramadol species in aqueous solution by using the B3LYP/6-31G* method.

\begin{tabular}{|c|c|c|c|c|c|c|c|}
\hline \multicolumn{8}{|c|}{ Tramadol $^{\mathrm{a}}$} \\
\hline \multirow{2}{*}{$\mathrm{H}$ atom } & \multicolumn{2}{|c|}{ Base } & \multicolumn{2}{|c|}{ Cationic } & \multicolumn{2}{|c|}{ Hydrochloride } & \multirow{2}{*}{$\operatorname{Exp}^{\mathbf{b}}$} \\
\hline & Gas & PCM & Gas & PCM & Gas & PCM & \\
\hline $20-\mathrm{H}$ & 2.37 & 2.49 & 2.61 & 1.89 & 1.80 & 2.30 & 2.27 \\
\hline $21-\mathrm{H}$ & 2.22 & 2.29 & 2.47 & 1.78 & 1.38 & 2.37 & 2.22 \\
\hline $22-\mathrm{H}$ & 2.67 & 2.46 & 1.54 & 0.71 & 3.00 & 3.28 & 2.27 \\
\hline $23-\mathrm{H}$ & 2.49 & 2.45 & 2.67 & 1.93 & 1.83 & 2.43 & 2.22 \\
\hline
\end{tabular}




\begin{tabular}{|c|c|c|c|c|c|c|c|}
\hline \multicolumn{8}{|c|}{ Tramadol $^{\mathbf{a}}$} \\
\hline \multirow{2}{*}{$\mathrm{H}$ atom } & \multicolumn{2}{|c|}{ Base } & \multicolumn{2}{|c|}{ Cationic } & \multicolumn{2}{|c|}{ Hydrochloride } & \multirow{2}{*}{$\operatorname{Exp}^{b}$} \\
\hline & Gas & PCM & Gas & PCM & Gas & PCM & \\
\hline $24-\mathrm{H}$ & 1.66 & 1.64 & 2.12 & 1.38 & 0.98 & 1.74 & 2.27 \\
\hline $25-\mathrm{H}$ & 2.20 & 2.22 & 2.57 & 1.90 & 1.47 & 2.46 & 2.22 \\
\hline $26-\mathrm{H}$ & 1.91 & 1.89 & 2.13 & 1.38 & 1.49 & 1.84 & 2.27 \\
\hline $27-\mathrm{H}$ & 1.86 & 1.83 & 2.24 & 1.54 & 1.19 & 1.90 & 2.22 \\
\hline $28-\mathrm{H}$ & 2.41 & 2.39 & 2.56 & 1.87 & 1.62 & 2.42 & 2.27 \\
\hline $29-\mathrm{H}$ & 2.87 & 3.04 & 3.98 & 3.05 & 2.03 & 3.43 & 2.81 \\
\hline $30-\mathrm{H}$ & 2.24 & 1.92 & 3.25 & 2.45 & 2.24 & 2.38 & 2.55 \\
\hline $31-\mathrm{H}$ & 0.32 & 0.43 & 1.14 & 0.46 & 0.33 & 0.64 & 5.12 \\
\hline $32-\mathrm{H}$ & 6.98 & 7.00 & 6.91 & 6.17 & 6.37 & 6.95 & 7.09 \\
\hline $33-\mathrm{H}$ & 7.34 & 7.27 & 7.21 & 6.52 & 6.55 & 7.22 & 7.07 \\
\hline $34-\mathrm{H}$ & 2.57 & 2.50 & 3.29 & 2.56 & 1.85 & 2.80 & 2.41 \\
\hline $35-\mathrm{H}$ & 2.30 & 1.90 & 3.13 & 2.39 & 1.35 & 1.90 & 2.41 \\
\hline $36-\mathrm{H}$ & 2.53 & 2.48 & 3.29 & 2.55 & 2.08 & 3.20 & 2.41 \\
\hline $37-\mathrm{H}$ & 2.72 & 2.78 & 3.50 & 2.86 & 1.70 & 3.08 & 2.55 \\
\hline $38-\mathrm{H}$ & 2.30 & 2.31 & 3.07 & 2.33 & 1.99 & 2.83 & 2.55 \\
\hline $39-\mathrm{H}$ & 1.66 & 1.50 & 2.63 & 1.93 & 0.54 & 1.70 & 2.55 \\
\hline $40-\mathrm{H}$ & 7.50 & 7.49 & 7.81 & 7.12 & 6.81 & 7.57 & 7.28 \\
\hline $41-\mathrm{H}$ & 6.70 & 6.72 & 7.09 & 6.43 & 6.05 & 6.80 & 7.07 \\
\hline $42-\mathrm{H}$ & 4.27 & 4.27 & 4.53 & 3.82 & 3.64 & 4.33 & 3.76 \\
\hline $43-\mathrm{H}$ & 3.95 & 3.97 & 4.07 & 3.31 & 3.21 & 3.87 & 3.76 \\
\hline $44-\mathrm{H}$ & 3.93 & 3.89 & 4.08 & 3.37 & 3.23 & 4.01 & 3.76 \\
\hline RMSD & \begin{tabular}{|l|}
1.01 \\
\end{tabular} & 1.00 & 0.96 & 1.08 & 1.24 & \begin{tabular}{|l|}
0.99 \\
\end{tabular} & \\
\hline
\end{tabular}

aThis work GIAO/B3LYP/6-31G* Ref. to TMS, ${ }^{\text {b} F r o m ~ R e f ~[24] . ~}$

In this study, the values in the gas phase were also included in the tables. Analyzing the RMSDs for the ${ }^{1} \mathrm{H}$ nucleus of all species, we observed that in good general correlations are observed for the three species with values between 1.24 and $0.96 \mathrm{ppm}$ and, in particular, the hydrochloride species in solution shows a low value because it is the compared species. The free base values in both media, closer than the corresponding cationic species, suggest that the free base could be protonated in solution. Suppose now the results for the $13 \mathrm{C}$ nucleus are compared. In that case, it is observed that the free base and hydrochloride species present similar correlations in the RMSDs (9.96-9.54 ppm), while lower concordances are observed in the cationic species in both media (10.36-10.03 ppm). Such differences could be associated with the different media recorded and calculated the spectra and calculations because better correlations are observed when the species are optimized using the B3LYP/6-311++G** method and, especially, the chemical shifts for the ${ }^{1} \mathrm{H}$ nucleus.

Table 14. Observed and calculated ${ }^{13} \mathrm{C}$ chemical shifts ( $\delta$ in ppm) for the three Tramadol species in aqueous solution by using the B3LYP/6-31G* method.

\begin{tabular}{|c|c|c|c|c|c|c|c|}
\hline \multicolumn{8}{|c|}{ Tramadol $^{\mathrm{a}}$} \\
\hline \multirow{2}{*}{$\mathrm{C}$ atoms } & \multicolumn{2}{|c|}{ Base } & \multicolumn{2}{|c|}{ Cationic } & \multicolumn{2}{|c|}{ Hydrochloride } & \multirow{2}{*}{$\operatorname{Exp}^{b}$} \\
\hline & Gas & PCM & Gas & PCM & Gas & PCM & \\
\hline 4-C & 38.4 & 37.8 & 36.6 & 35.8 & 36.8 & 36.8 & 40.21 \\
\hline $5-\mathrm{C}$ & 69.3 & \begin{tabular}{|l|}
69.8 \\
\end{tabular} & \begin{tabular}{|l|}
68.7 \\
\end{tabular} & \begin{tabular}{|l|}
69.4 \\
\end{tabular} & 69.7 & 69.7 & 73.87 \\
\hline 6-C & 20.6 & 19.6 & 18.4 & 18.1 & 23.4 & 19.6 & 26.16 \\
\hline $7-\mathrm{C}$ & 36.7 & 37.4 & 34.1 & 36.2 & 35.7 & 36.9 & 40.39 \\
\hline $8-\mathrm{C}$ & 20.4 & 20.2 & 18.6 & 18.7 & 19.2 & 19.1 & 24.47 \\
\hline 9-C & 17.1 & 16.7 & 15.2 & 15.4 & 16.5 & 16.2 & 21.16 \\
\hline $10-\mathrm{C}$ & 50.6 & 51.7 & 56.6 & 55.5 & 52.4 & 51.4 & 59.33 \\
\hline $11-\mathrm{C}$ & 136.7 & 137.3 & 129.7 & 130.5 & 136.0 & 135.6 & 150.0 \\
\hline $12-\mathrm{C}$ & 100.7 & 100.8 & 99.3 & 98.9 & 101.0 & \begin{tabular}{|l|}
100.1 \\
\end{tabular} & 111.52 \\
\hline $13-\mathrm{C}$ & 103.1 & 102.9 & 100.7 & 101.3 & 102.9 & 102.5 & 117.22 \\
\hline 14-C & 39.2 & \begin{tabular}{|l|}
40.1 \\
\end{tabular} & 37.5 & 37.9 & 35.5 & 37.6 & 44.77 \\
\hline $15-\mathrm{C}$ & 33.8 & 34.5 & 32.8 & 32.7 & 32.0 & 30.7 & 40.60 \\
\hline $16-\mathrm{C}$ & 143.8 & 144.6 & 145.6 & 146.3 & 144.4 & 144.9 & 159.1 \\
\hline $17-\mathrm{C}$ & 114.9 & 115.3 & \begin{tabular}{|l|}
117.7 \\
\end{tabular} & \begin{tabular}{|l|}
118.0 \\
\end{tabular} & 115.5 & 116.1 & 129.06 \\
\hline
\end{tabular}




\begin{tabular}{|c|c|c|c|c|c|c|c|}
\hline \multicolumn{8}{|c|}{ Tramadol $^{\mathbf{a}}$} \\
\hline \multirow{2}{*}{$\mathrm{C}$ atoms } & \multicolumn{2}{|c|}{ Base } & \multicolumn{2}{|c|}{ Cationic } & \multicolumn{2}{|c|}{ Hydrochloride } & \multirow{2}{*}{$\operatorname{Exp}^{\mathbf{b}}$} \\
\hline & Gas & PCM & Gas & PCM & Gas & PCM & \\
\hline $18-\mathrm{C}$ & 94.5 & 94.9 & 98.4 & 99.0 & 95.3 & 95.9 & 111.12 \\
\hline 19-C & 45.1 & 45.8 & 45.9 & 46.4 & 45.1 & 45.9 & 54.96 \\
\hline RMSD & 9.86 & 9.54 & 10.36 & 10.03 & 9.92 & 9.96 & \\
\hline
\end{tabular}

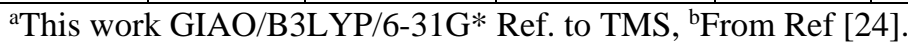

\subsection{Electronic spectrum.}

The electronic spectra for the three tramadol species were also predicted in an aqueous solution because tramadol hydrochloride is freely soluble in water, as reported in the literature [24]. These theoretical spectra were obtained using the Time-dependent DFT calculations (TDDFT) with the Gaussian program and the B3LYP/6-31G* method [35]. The experimental spectrum was recorded for tramadol hydrochloride in methanol from 200 to $400 \mathrm{~nm}$ [24]. All spectra are compared in Figure 11. It is possible to observe that the experimental UV spectrum shows absorption maxima at $217 \mathrm{~nm}$ and $272 \mathrm{~nm}$ while the predicted spectrum for the free base present maxima at 180 and $245 \mathrm{~nm}$ and a shoulder at $212 \mathrm{~nm}$. In the cationic species, only two maxima are observed at 212 and $250 \mathrm{~nm}$. In the UV spectrum of hydrochloride form, they are observed two maxima at 245 and $290 \mathrm{~nm}$.

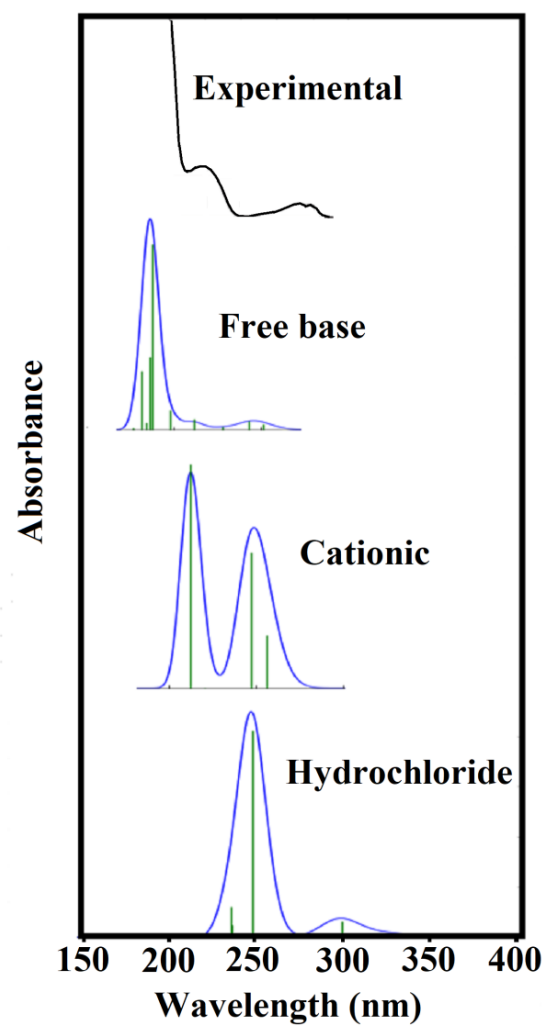

Figure 11. Experimental electronic spectrum of hydrochloride tramadol in methanol [24] compared with the corresponding predicted for the three species in aqueous solution using the B3LYP/6-31G* method.

These results show that part of the free base is protonated in solution because the shoulder and the maximum respectively at 212 and $245 \mathrm{~nm}$ correspond to bands of cation while part of hydrochloride species is as cationic one because the two experimental bands at $217 \mathrm{~nm}$ and $272 \mathrm{~nm}$ are in agreement with a band of the cation $(212 \mathrm{~nm})$ and other of free base protonated $(290 \mathrm{~nm})$. The band at $180 \mathrm{~nm}$ observed for the free base cannot be seen experimentally because the experimental spectrum was recorded between 200 and $400 \mathrm{~nm}$. These studies show that the three species can be present in a solution of hydrochloride tramadol 
and that the bands can be attributed to $\pi \rightarrow \pi^{*}$ transitions due to the $\mathrm{C}=\mathrm{C}$ double bonds, as predicted by the NBO analysis and in agreement with literature data $[49,50]$.

\section{Conclusions}

In this research, three species of narcotic tramadol agent's theoretical structures were studied in the gas phase and aqueous solution by using the functional hybrid B3LYP with the 6-31G* basis set. Comparisons of predicted infrared, Raman, ${ }^{1} \mathrm{H}$, and ${ }^{13} \mathrm{C}$ NMR and electronic spectra for the free base, cationic, and hydrochloride species of tramadol with the corresponding experimental ones have evidenced reasonable correlations for the cationic species showing that this species present in the solid phase and in solution. The vibrational studies have revealed that the species cationic is present in the solid phase because the most intense band predicted for the hydrochloride in infrared and Raman spectra is not observed in the experimental spectra. The harmonic force fields, together with the normal internal coordinates and scaling factors, have allowed the complete vibrational assignments of 126 , 129, and 132 vibration modes expected for a free base, cationic, and hydrochloride species, respectively, by using the SQMFF methodology. The cationic species evidence the most negative solvation energy and higher hydration in solution in agreement with its lower stability, while the hydrochloride species is the most reactive in solution. MK charges and NBO and AIM studies support cationic species' instability due to the positive charge on $\mathrm{N}$ atom. Comparisons of the experimental UV spectrum of hydrochloride tramadol with the predicted for the three species suggest that the free base, cationic, and hydrochloride species can be present in solution.

\section{Funding}

This research received no external funding.

\section{Acknowledgments}

This work was supported with grants from CIUNT Project N ${ }^{\circ}$ 26/D608 (Consejo de Investigaciones, Universidad Nacional de Tucumán). The author would like to thank Prof. Tom Sundius for his permission to use MOLVIB.

\section{Conflicts of Interest}

The authors declare no conflict of interest.

\section{References}

1. Veber. D.F.; Johnson, S.R.; Cheng, H.-Y; Brian, R.; Ward, K.W.; Kopple, K.D. Molecular Properties that influence the oral bioavailability of drug candidates. J. Med. Chem. 2002, 45, 2615-2623, https://doi.org/10.1021/jm020017n.

2. Lipinski, C.A.; Lombardo, F.; Dominy, B.W.; Feeney, P.J. Experimental and computational approaches to estimate solubility and permeability in drug discovery and development setting. Advanced Drug Delivery Reviews 2001, 46, 3-26, https://doi.org/10.1016/s0169-409x(00)00129-0.

3. Brandán, S.A. Why morphine is a molecule chemically powerful. Their comparison with cocaine. Indian Journal of Applied Research 2017, 7, 511-528.

4. Rudyk, R.A.; Brandán, S.A. Force field, internal coordinates and vibrational study of alkaloid tropane hydrochloride by using their infrared spectrum and DFT calculations. Paripex A Indian Journal of Research 2017, 6, 616-623. 
5. Romani, D.; Brandán, S.A. Vibrational analyses of alkaloid cocaine as free base, cationic and hydrochloride species based on their internal coordinates and force fields. Paripex A Indian Journal of Research 2017, 6, 587-602.

6. Iramain, M.A.; Ledesma, A.E.; Brandán, S.A. Analyzing the effects of halogen on properties of a halogenated series of $\mathrm{R}$ and $\mathrm{S}$ enantiomers analogues alkaloid cocaine-X, X=F, Cl, Br, I. Paripex A Indian Journal of Research, 2017, 6, 454-463.

7. Brandán, S.A. Understanding the potency of heroin against to morphine and cocaine. IJSRM, International Journal of Science and Research Methodology 2018, 12, 97-140.

8. Rudyk, R.A.; Checa, M.A.; Guzzetti, K.A.; Iramain, M.A.; Brandán, S.A. Behaviour of N-CH${ }_{3} \mathrm{Group}_{\text {in }}$ Tropane Alkaloids and correlations in their Properties. IJSRM, International Journal of Science And Research Methodology 2018, 10, 70-97.

9. Rudyk, R.A.; Checa, M.A.; Catalán, C.A.N.; Brandán, S.A. Structural, FT-IR, FT-Raman and ECD spectroscopic studies of free base, cationic and hydrobromide species of scopolamine alkaloid. J. Mol. Struct. 2019, 1180, 603-617, https://doi.org/10.1016/j.molstruc.2018.12.040.

10. Iramain, M.A.; Brandán, S.A. Structural and vibrational properties of three species of anti-histaminic diphenhydramine by using DFT calculations and the SQM approach. Journal: To Chemistry Journal 2018, 1, 105-130.

11. Márquez, M.J.; Iramain, M.A.; Brandán, S.A. Ab-initio and Vibrational studies on Free Base, Cationic and Hydrochloride Species Derived from Antihistaminic Cyclizine agent. International Journal of Science and Research Methodology 2019, 11, 53-87.

12. Manzur, M.E.; Rudyk, R.A.; Brandán, S.A. Evaluating properties of free base, cationic and hydrochloride Species of potent psychotropic 4-Bromo-2,5-dimethoxyphenethylamine drug. International Journal of Current Advanced Research 2019, 8, 17166-17170.

13. Iramain, M.A.; Ruiz Hidalgo, J.; Brandán, S.A. Predicting properties of species derived from N-(1H-indol3-ylmethyl)-N,N-dimethylamine, Gramine, a indol alkaloid. International Journal of Current Advanced Research 2019, 8, 18113-18124.

14. Romani, D.; Ruiz Hidalgo, J.; Iramain, M.A.; Brandán, S.A. Structures, Reactivities and Vibrational Study of Species Derived from the Adrenergic $\alpha_{2}$ Receptor Agonist Guanfacine. International Journal of Science And Research Methodology 2019, 12, 74-98.

15. Manzur, M.E.; Brandán, S.A. S(-) and R(+) Species Derived from Antihistaminic Promethazine Agent: Structural and Vibrational Studies. Heliyon 2019, 5, https://doi.org/10.1016/j.heliyon.2019.e02322.

16. Márquez, M.J.; Brandán, S.A. DFT study of Species Derived from the Narcotic Antagonist Naloxone, Biointerface Research in Applied Chemistry 2020, 10, 8096-8116, https://doi.org/10.33263/BRIAC102.096116.

17. Ruiz Hidalgo, J.; Iramain, M.A.; Brandán, S.A. Structural Studies and Spectroscopic properties of Quinolizidine Alkaloids (+) and (-)-Lupinine in different media. J. Mater. Environ. Sci. 2019, 10, 854-871.

18. Contreras, C.D.; Ledesma, A E.; Zinczuk, J.; Brandán, S.A. Vibrational study of tolazoline hydrochloride by using FTIR-Raman and DFT calculations. Spectrochim. Acta A 2011, 79, 1710-1714, https://doi.org/10.1016/j.saa.2011.05.041.

19. Romano, E.; Brizuela, A.B.; Guzzetti, K.; Brandán, S.A. An experimental and theoretical study on the hydration in aqueous medium of the anti-hypertensive agent tolazoline hydrochloride. J. Mol. Struct. 2013, 1037, 393-401, http://dx.doi.org/10.1016/j.molstruc.2013.01.028.

20. Romano, E.; Davies, L.; Brandán, S.A. Structural properties and FTIR-Raman spectra of the antihypertensive, clonidine hydrochloride agent and their dimeric species. J. Mol. Struct. 2017, 1133, 226-235, http://dx.doi.org/10.1016/j.molstruc.2016.12.008.

21. Brandán, S.A. Correlations in hydrochloride drugs with diverse pharmacological activities. Role of N-H $\cdots \mathrm{Cl}$ bonds. Biointerface Research in Applied Chemistry 2020, 10, 5536-5547, https://doi.org/10.33263/BRIAC103.536547.

22. Guzzetti, K.A.; Iramain, M.A.; Rudyk, R.A.; Manzur, M.E.; Brandán, S.A., Vibrational Studies of Species Derived from Potent $\mathrm{S}(+)$ and $\mathrm{R}(-)$ Ecstasy Stimulant by Using Ab-initio Calculations and the SQM Approach. Biointerface Research in Applied Chemistry 2020, 10, 6783-6809, https://doi.org/10.33263/BRIAC106.67836809.

23. Brandán, S.A. Normal internal coordinates, Force fields and vibrational study of Species Derived from Antiviral amantadine. Int. J. Quantum Chem. 2021, 121, https://doi.org/10.1002/qua.26425.

24. Smyj, R.; Wang, X-P.; Han, F. Chapter 11-Tramadol Hydrochloride. In: Profiles of Drug Substances, Excipients, and Related Methodology. Elsevier Inc.ISSN 1871-5125, Volume 38, 2013; http://dx.doi.org/10.1016/B978-0-12-407691-4.00011-3.

25. Becke, A.D. Density-functional exchange-energy approximation with correct asymptotic behavior. Phys. Rev. 1988, A38, 3098-3100, https://doi.org/10.1103/PhysRevA.38.3098.

26. Lee, C.; Yang, W.; Parr, R.G. Development of the Colle-Salvetti correlation-energy formula into a functional of the electron density. Phys. Rev. 1988, B37, 785-789, https://doi.org/10.1103/PhysRevB.37.785.

27. Pulay, P.; Fogarasi, G.; Pongor, G.; Boggs, J.E.; Vargha, A. Combination of theoretical ab initio and experimental information to obtain reliable harmonic force constants. Scaled quantum mechanical (QM) 
force fields for glyoxal, acrolein, butadiene, formaldehyde, and ethylene. Journal of the American Chemical Society 1983, 105, 7037-7047, https://doi.org/10.1021/ja00362a005

28. Rauhut, G.; Pulay, P. Transferable Scaling Factors for Density Functional Derived Vibrational Force Fields. J. Phys. Chem. 1995, 99, 3093-3100, https://doi.org/10.1021/j100010a019

29. Sundius, T. Scaling of ab-initio force fields by MOLVIB. Vib. Spectrosc. 2002, 29, 89-95, https://doi.org/10.1016/S0924-2031(01)00189-8.

30. Tramadol Hydrochloride, European Pharmacopoeia. seventh ed., European Directorate for the Quality of Medicines \& Healthcare (EDQM), Council of Europe, Strasbourg, 2010; pp. 3118-3119.

31. Kaduk, J.A.; Zhong, K.; Gindhart, A.M.; Blanton, T.N. Crystal structure of tramadol hydrochloride, C16H26NO2Cl. Powder Diffraction 2015, 30, 242-249, https://doi.org/10.1017/S088571561500041X.

32. Siddaraju, B.P.; Jasinski, J.P.; Golen, J.A.; Yathirajan, H.S.; Raju, C.R. Tramadol hydro-chloride-benzoic acid (1/1). Acta Crystallogr Sect E Struct Rep Online 2011, 67, o2351-02351, https://doi.org/10.1107/S1600536811032181.

33. Bag, P.P.; Reddy, C.M. Tramadol Hydrochloride and its Acetonitrile Solvate: Crystal Structure Analysis and Thermal Studies. Proceedings of the National Academy of Sciences, India Section A: Physical Sciences 2014, 84, 235-242, https://doi.org/10.1007/s40010-013-0118-0.

34. Nielsen, A.B.; Holder, A.J. Gauss View 5.0, User's Reference, GAUSSIAN Inc., Pittsburgh, PA, 2008.

35. Frisch, M.J.; Trucks, G.W.; Schlegel, H.B.; Scuseria, G.E.; Robb, M.A.; Cheeseman, J.R.; Scalmani, G.; Barone, V.; Mennucci, B.; Petersson, G.A.; Nakatsuji, H.; Caricato, M.; Li, X.; Hratchian, H.P.; Izmaylov, A.F.; Bloino, J.; Zheng, G.; Sonnenberg, J.L.; Hada, M.; Ehara, M.; Toyota, K.; Fukuda, R.; Hasegawa, J.; Ishida, M.; Nakajima, T.; Honda, Y.; Kitao, O.; Nakai, H.; Vreven, T.; Montgomery, J.A.; Peralta, J.E.; Ogliaro, F.; Bearpark, M.; Heyd, J.J.; Brothers, E.; Kudin, K.N.; Staroverov, V.N.; Kobayashi, R.; Normand, J.; Raghavachari, K.; Rendell, A.; Burant, J.C.; Iyengar, S.S.; Tomasi, J.; Cossi, M.; Rega, N.; Millam, J.M.; Klene, M.; Knox, J.E.; Cross, J.B.; Bakken, V.; Adamo, C.; Jaramillo, J.; Gomperts, R.; Stratmann, R.E.; Yazyev, O.; Austin, A.J.; Cammi, R.; Pomelli, C.; Ochterski, J.W.; Martin, R.L.; Morokuma, K.; Zakrzewski, V.G.; Voth, G.A.; Salvador, P.; Dannenberg, J.J.; Dapprich, S.; Daniels, A.D.; Farkas, O.; Foresman, J.B.; Ortiz, J.; Cioslowski, J.; Fox, D.J. Gaussian, Inc., Wallingford CT, 2009.

36. Miertus, S.; Scrocco, E.; Tomasi, J. Electrostatic interaction of a solute with a continuum. Chem. Phys. 1981, 55, 117-129, https://doi.org/10.1016/0301-0104(81)85090-2.

37. Tomasi, J.; Persico, J. Molecular Interactions in Solution: An Overview of Methods Based on Continous Distributions of the Solvent. Chem. Rev. 1994, 94, 2027-2094, https://doi.org/10.1021/cr00031a013.

38. Marenich, A.V.; Cramer, C.J.; Truhlar, D.G. Universal solvation model based on solute electron density and a continuum model of the solvent defined by the bulk dielectric constant and atomic surface tensions. $J$. Phys. Chem. 2009, B113, 6378-6396, https://doi.org/10.1021/jp810292n.

39. Keresztury, G.; Holly, S.; Besenyei, G.; Varga, J.; Wang, A.; Durig, J.R. Vibrational spectra of monothiocarbamates-II. IR and Raman spectra, vibrational assignment, conformational analysis and ab initio calculations of S-methyl-N,N-dimethylthiocarbamate. Spectrochimica Acta Part A: Molecular Spectroscopy 1993, 49, 2007-2026, https://doi.org/10.1016/S0584-8539(09)91012-1.

40. Michalska, D.; Wysokiński, R. The prediction of Raman spectra of platinum(II) anticancer drugs by density functional theory. Chemical Physics Letters 2005, 403, 211-217, https://doi.org/10.1016/j.cplett.2004.12.096.

41. Glendening, E.; Badenhoop, J.K.; Reed, A.D.; Carpenter, J.E.; Weinhold, F. NBO 3.1; Theoretical Chemistry Institute. University of Wisconsin; Madison, WI, 1996.

42. Bader, R.F.W. Atoms in Molecules, A Quantum Theory. Oxford University Press, Oxford, 1990.

43. Biegler-Köning, F.; Schönbohm, J.; Bayles, D. AIM2000; A Program to Analyze and Visualize Atoms in Molecules. J. Comput. Chem. 2001, 22, http://dx.doi.org/10.1002/1096987X(20010415)22:5\%3C545::AID-JCC1027\%3E3.0.CO;2-Y.

44. Besler, B.H.; Merz, Jr. K.M.; Kollman, P.A. Atomic charges derived from semiempirical methods. J. Comp. Chem. 1990, 11, 431-439, https://doi.org/10.1002/jcc.540110404.

45. Ugliengo, P. MOLDRAW Program. University of Torino, Dipartimento Chimica IFM, Torino, Italy, 1998.

46. Parr, R.G.; Pearson, R.G. Absolute hardness: companion parameter to absolute electronegativity. Journal of the American Chemical Society 1983, 105, 7512-7516, https://doi.org/10.1021/ja00364a005.

47. Ditchfield, R. Self-consistent perturbation theory of diamagnetism. Molecular Physics 1974, 27, 789-807, https://doi.org/10.1080/00268977400100711.

48. Experimental available ATR and Raman spectra of topiramate from: https://spectrabase.com/spectrum/.

49. Minteguiaga, M.; Dellacassa, E.; Iramain, M.A.; Catalán, C.A.N.; Brandán, S.A. Synthesis, spectroscopic characterization and structural study of 2-isopropenyl-3-methylphenol, carquejiphenol, a carquejol derivative with potential medicinal use. Journal of Molecular Structure 2018, 1165, 332-343, https://doi.org/10.1016/j.molstruc.2018.04.001.

50. Minteguiaga, M.; Dellacassa, E.; Iramain, M.A.; Catalán, C.A.N.; Brandán, S.A. FT-IR, FT-Raman, UVVis, NMR and structural studies of carquejyl acetate, a distinctive component of the essential oil from Baccharis trimera (less.) DC. (Asteraceae). Journal of Molecular Structure 2019, 1177, 499-510, https://doi.org/10.1016/j.molstruc.2018.10.010. 